\title{
Year In Review 2006
}

\section{Year in review: communicable disease surveillance, New South Wales, 2006}

\section{Communicable Diseases Branch, NSW Department of Health}

In this issue, we review the trends in reports of notifiable diseases among NSW residents received by the NSW Public Health Units (PHU) for 2006. Readers interested in the details of notifications for specific diseases are referred to Tables 1-5, where diseases are reported by: year of onset, month of onset, Area Health Service (AHS), age group and sex. Table 6 shows the number of people with selected notifiable conditions who were reported to have died at the time of follow-up by their local PHU.

\section{Trends}

Among the 47608 NSW residents with medical conditions notified by doctors, hospital staff, and laboratory staff for 2006, highlights included:

\section{Conditions most frequently reported}

- Chlamydia: 11864 cases (173 per 100000 people), with the highest crude rates by geographical area in the South Eastern Sydney/Illawarra (Randwick region), Hunter/New England (Newcastle region) and Sydney South West (Camperdown region) AHSs

- Pertussis: 4918 cases (73 per 100000 people), with the highest crude rates in the Greater Western (Broken Hill and Dubbo regions) and Greater Southern (Albury region) Health Areas. Note, a proportion of pertussis notifications may have been false-positive tests caused by the performance of a commonly used serology test kit (see http://www.health.nsw.gov.au/infect/pdf/ false_pertussis_tests.pdf)

- Hepatitis C: 4470 cases (65 per 100000 people), with the highest crude rates in the Sydney South West (Camperdown region), North Coast (Lismore region) and Greater Western (Bathurst region) AHSs

- Hepatitis B: 2543 cases (37 per 100000 people), with the highest crude rates in the Sydney South West and Sydney West (Parramatta region) AHSs
- Salmonella infections: 2058 cases (26 per 100000 population), with the highest crude rates in the North Coast (Lismore region), Greater West (Dubbo region) and Hunter New England (Tamworth region) AHSs.

\section{Conditions with the most meaningful declines in the} number of notifications compared with previous years

- Hepatitis B: 2543 cases, steadily declining from 4458 cases in 2001, with the most pronounced fall (43\% since 2002) in the 35 to 44 year age group, possibly as a result of the ongoing impact of immunisation

- Pneumococcal disease (invasive): 564 cases, a continued decline from 906 in 2004 and most pronounced in the 0-to-2-year age group, possibly a result of the inclusion of the pneumococcal vaccination on the universal childhood vaccination schedule in early 2005

- Meningococcal disease: 107 cases, a continued decline from 253 in 2000, the lowest number of notifications since laboratory reporting began in 1991 and in part due to the introduction of meningococcal $\mathrm{C}$ vaccination in late 2003

- Leptospirosis: 17 cases, down from 66 in 2001, the cause of the decline is unclear.

\section{Conditions with the most meaningful increases in the} number of notifications compared with previous years

- Chlamydia: 11864 cases, continuing its rise since it became notifiable in the late 1990s

- Infectious syphilis: re-emerging as a significant issue in the gay community in late 2006

- Barmah Forest virus infection: 644 cases, due to outbreaks mainly in coastal areas of rural NSW in early 2006

- Ross River virus infection: 1225 cases, up from 583 in 2005, due to outbreaks across rural NSW in early 2006 
- Gastroenteritis in institutions: 10636 cases associated with 436 outbreaks, mostly due to norovirus infections

- Mumps: 154 cases, up from 111 in 2005, mainly in young adults and the highest number of laboratory notifications since laboratory reporting began in 1991

- Legionnaires' disease, due to infection with Legionella pneumophila: 54 cases, in part due to outbreaks in western and northern Sydney

- Measles: 48 cases, due to two outbreaks, one in March 2006 related to contact at a hospital emergency department and the second, larger outbreak, in people associated with a national spiritual tour.

Note that the apparent increase in giardiasis (1720 cases) and verotoxigenic Escherichia coli infections (10 cases) are probably related to changes in laboratory testing practices resulting in a higher proportion of samples tested for these organisms than in the past.

\section{Conditions least frequently reported}

There were no reported cases of avian influenza, botulism, chancroid, diphtheria, donovanosis, granuloma inguinale, plague, polio, rabies/lyssavirus, SARS, smallpox, tularaemia, typhus, viral haemorrhagic fevers or yellow fever in NSW in 2006.

\section{Conditions associated with the largest numbers of reported deaths}

Deaths reported via the surveillance mechanisms for notifiable conditions may not include all deaths associated with these conditions. PHUs routinely investigate all cases of some notifiable conditions (eg, tuberculosis, measles, meningococcal disease) in order to implement control measures; the investigations are likely to identify associated deaths. However, there are other notifiable conditions (eg, chlamydia and gonorrhoea) where PHUs do not conduct routine investigations and for which deaths will not be identified as part of the notification or public health management process. Conversely, some deaths in patients following notification may be due to conditions other than that notified. Deaths were most frequently reported for the following notifiable diseases:

- Invasive pneumococcal disease: 61 deaths

- HIV infection: 36 deaths, including 13 people who died from AIDS, and 23 people with HIV infection who died of causes other than AIDS

- Tuberculosis: 21 deaths.

\section{Outbreaks and threats}

Several notable disease outbreaks and threats were reported in 2006 in NSW. These included:

- Outbreaks of Legionnaires' disease in western Sydney in January $2006^{1}$ and northern Sydney in March $2006^{2}$ thought to be related to contaminated cooling towers.

- Two outbreaks of measles ${ }^{2}$

- An outbreak of keratoconjunctivitis in patients of an eye clinic in regional NSW in March $2006^{2}$

- Four cases of lymphogranuloma venereum identified in early 2006, the first cases in NSW 3

- A cluster of cases of Salmonella Saint-Paul infection in October 2006 linked to contaminated rockmelons ${ }^{4}$

- Three cases of cholera in November 2006 linked to consumption of raw imported whitebait. ${ }^{5}$

\section{Conclusions}

Sexually transmitted infections, gastroenteritis (particularly norovirus) and arboviruses continue to be significant public health problems in NSW. Much progress has been made with other diseases, such as hepatitis B, invasive pneumococcal disease and meningococcal disease, in which declines were identified. Outbreaks of diseases, that have largely been brought under control, for example measles and mumps (where many young adults remain unvaccinated), continue to pose a threat.

We thank all those general and specialist medical practices, laboratories, hospitals, schools, child-care centres, and others, who have notified diseases of public health significance to their local PHUs for investigation and control.

\section{References}

1. NSW Department of Health Communicable Diseases Report, NSW, for January and February 2006. N S W Public Health Bull 2006; 17(3-4): 58-9.

2. NSW Department of Health Communicable Diseases Report, NSW, for March and April 2006. N S W Public Health Bull 2006; 17(5-6): 88-91.

3. NSW Department of Health Communicable Diseases Report, NSW, for July and August 2006. N S W Public Health Bull 2006; 17(9-10): 154-5.

4. NSW Department of Health Communicable Diseases Report, NSW, for September and October 2006. N S W Public Health Bull 2006; 17(11-12): 182-3.

5. NSW Department of Health Communicable Diseases Report, NSW, for November and December 2006. N S W Public Health Bull 2007; 18(1-2): 28-32. 
Table 1. Disease notifications by year of onset of illness ${ }^{\mathrm{a}}$, NSW, 1991-2006

\begin{tabular}{|c|c|c|c|c|c|c|c|c|c|c|c|c|c|c|c|c|}
\hline Condition & 1991 & 1992 & 1993 & 1994 & 1995 & 1996 & 1997 & 1998 & 1999 & 2000 & 2001 & 2002 & 2003 & 2004 & 2005 & 2006 \\
\hline Anthrax & 0 & 0 & 0 & 0 & 0 & 0 & 0 & 0 & 0 & 0 & 0 & 0 & 0 & 0 & 0 & 1 \\
\hline Adverse events after immunisation & 9 & 31 & 23 & 40 & 28 & 56 & 70 & 95 & 16 & 42 & 111 & 178 & 219 & 184 & 106 & 65 \\
\hline Arboviral infection & 409 & 343 & 656 & 381 & 539 & 1227 & 1806 & 783 & 1220 & 980 & 1191 & 664 & 1024 & 1148 & 1087 & 1920 \\
\hline Barmah Forest virus ${ }^{b}$ & 6 & 6 & 25 & 39 & 271 & 172 & 185 & 134 & 249 & 197 & 401 & 396 & 451 & 403 & 448 & 644 \\
\hline Ross River virus $^{\mathrm{b}}$ & 297 & 324 & 599 & 331 & 236 & 1031 & 1598 & 583 & 952 & 750 & 717 & 182 & 494 & 701 & 583 & 1225 \\
\hline Other ${ }^{b}$ & 106 & 13 & 32 & 11 & 32 & 24 & 23 & 66 & 19 & 33 & 73 & 86 & 79 & 44 & 56 & 51 \\
\hline Blood lead level $\geq 15 \mu \mathrm{g} / \mathrm{dL}^{\mathrm{b}}$ & \multicolumn{5}{|c|}{ Not notifiable until December 1996} & & 710 & 874 & 691 & 985 & 513 & 516 & 338 & 304 & 234 & 281 \\
\hline Botulism & 0 & 0 & 0 & 0 & 0 & 0 & 0 & 0 & 1 & 0 & 0 & 0 & 0 & 1 & 0 & 0 \\
\hline Brucellosis ${ }^{b}$ & 2 & 2 & 4 & 4 & 2 & 1 & 3 & 3 & 2 & 1 & 1 & 2 & 3 & 7 & 3 & 9 \\
\hline Chancroid ${ }^{b}$ & Not no & tifiable & until De & ecembe & 1998 & & & & 1 & 0 & 0 & 0 & 0 & 0 & 0 & 0 \\
\hline Chlamydia trachomatis infection ${ }^{b}$ & Not no & tifiable & until Ac & ugust 19 & 998 & & & & 2469 & 3509 & 4500 & 5823 & 7788 & 10020 & 11285 & 11864 \\
\hline Cholera $^{b}$ & 1 & 0 & 1 & 0 & 1 & 3 & 1 & 1 & 2 & 0 & 1 & 1 & 0 & 1 & 0 & 3 \\
\hline Creutzfeldt-Jakob disease $^{b}$ & Not no & tifiable & until $A p$ & oril 2004 & & & & & & & & & & 6 & 8 & 8 \\
\hline Cryptosporidiosis $^{\mathrm{b}}$ & Not no & tifiable & until De & ecembe & r 1996 & & 157 & 1130 & 121 & 133 & 195 & 306 & 203 & 357 & 849 & 779 \\
\hline Food-borne illness (NOS)e & 2765 & 253 & 106 & 213 & 270 & 211 & 255 & 201 & 151 & 147 & 56 & 41 & 1071 & 550 & 309 & 507 \\
\hline Gastroenteritis (institutional) & 158 & 406 & 443 & 296 & 1359 & 554 & 939 & 738 & 673 & 697 & 775 & 1752 & 3583 & 12784 & 1395 & 10636 \\
\hline Giardiasis $^{b}$ & Not no & tifiable & until Ac & ıgust 19 & 998 & & & & 1091 & 978 & 967 & 864 & 1028 & 1235 & 1447 & 1720 \\
\hline Gonorrhoeab $^{\mathrm{b}}$ & 392 & 491 & 382 & 357 & 428 & 522 & 636 & 1054 & 1291 & 1060 & 1364 & 1527 & 1328 & 1442 & 1579 & 1696 \\
\hline Haemolytic uraemic syndrome & Not no & tifiable & until De & ecembe & 1996 & & 3 & 6 & 11 & 9 & 2 & 7 & 5 & 9 & 11 & 11 \\
\hline H. influenzae type b & 212 & 217 & 124 & 61 & 29 & 13 & 17 & 11 & 13 & 8 & 7 & 10 & 6 & 5 & 7 & 11 \\
\hline Hib epiglottitis ${ }^{b}$ & 15 & 57 & 32 & 21 & 6 & 2 & 5 & 1 & 2 & 2 & 1 & 1 & 0 & 3 & 0 & 1 \\
\hline Hib meningitis ${ }^{b}$ & 48 & 103 & 53 & 17 & 11 & 4 & 3 & 3 & 3 & 1 & 1 & 1 & 0 & 0 & 2 & 0 \\
\hline Hib septicaemiab & 11 & 26 & 24 & 12 & 8 & 3 & 1 & 4 & 6 & 4 & 2 & 3 & 1 & 2 & 4 & 6 \\
\hline Hib infection (NOS) ${ }^{b}$ & 138 & 31 & 15 & 11 & 4 & 4 & 8 & 3 & 2 & 1 & 3 & 5 & 5 & 0 & 1 & 4 \\
\hline Hepatitis $A^{b}$ & 1119 & 901 & 579 & 585 & 614 & 958 & 1426 & 927 & 421 & 201 & 197 & 149 & 124 & 137 & 83 & 95 \\
\hline Hepatitis B & 1492 & 3169 & 3603 & 3984 & 4007 & 3505 & 3167 & 2957 & 3513 & 3973 & 4558 & 3547 & 2844 & 2812 & 2742 & 2543 \\
\hline Hepatitis B: acute viral & 409 & 112 & 95 & 74 & 61 & 43 & 53 & 58 & 77 & 100 & 94 & 88 & 74 & 53 & 56 & 54 \\
\hline Hepatitis B: other ${ }^{b}$ & 1083 & 3057 & 3508 & 3910 & 3946 & 3462 & 3114 & 2899 & 3436 & 3873 & 4464 & 3459 & 2770 & 2759 & 2686 & 2489 \\
\hline Hepatitis C & 851 & 3895 & 5897 & 7820 & 6878 & 7001 & 6925 & 7206 & 8602 & 8293 & 8659 & 6694 & 5248 & 4916 & 4365 & 4470 \\
\hline Hepatitis C: acute viral ${ }^{b}$ & 22 & 26 & 22 & 16 & 32 & 18 & 19 & 112 & 112 & 222 & 295 & 151 & 127 & 59 & 43 & 40 \\
\hline Hepatitis C: other ${ }^{b}$ & 829 & 3869 & 5875 & 7804 & 6846 & 6983 & 6906 & 7094 & 8490 & 8071 & 8364 & 6543 & 5121 & 4857 & 4322 & 4430 \\
\hline Hepatitis $D^{b}$ & 0 & 8 & 12 & 19 & 19 & 9 & 11 & 3 & 14 & 12 & 11 & 9 & 12 & 14 & 15 & 15 \\
\hline Hepatitis $\mathrm{E}^{\mathrm{b}}$ & 0 & 0 & 1 & 2 & 0 & 3 & 6 & 4 & 7 & 9 & 6 & 6 & 6 & 8 & 7 & 10 \\
\hline HIV/AIDS & & & & & & & & & & & & & & & & \\
\hline HIV infection ${ }^{b}$ & 822 & 694 & 590 & 502 & 537 & 447 & 422 & 403 & 378 & 356 & 340 & 394 & 413 & 408 & 395 & 371 \\
\hline AIDS & 441 & 433 & 483 & 555 & 483 & 376 & 214 & 181 & 133 & 134 & 102 & 117 & 148 & 100 & 109 & 84 \\
\hline Influenza & & & & & & & & & & & 244 & 1012 & 861 & 1011 & 1414 & 616 \\
\hline Influenza - Type $\mathrm{A}^{\mathrm{b}}$ & Not no & tifiable & until $D \in$ & ecembe & 2000 & & & & & & 216 & 770 & 767 & 797 & 1055 & 420 \\
\hline Influenza - Type $\mathrm{B}^{\mathrm{b}}$ & Not no & tifiable & until De & ecembe & 2000 & & & & & & 27 & 241 & 55 & 161 & 280 & 150 \\
\hline Influenza - Types A \& B & Not no & tifiable & until $D \in$ & ecembe & 2003 & & & & & & & & & 26 & 65 & 37 \\
\hline Influenza - Type (NOS) ${ }^{\text {b }}$ & Not no & tifiable & until De & ecembe & 2000 & & & & & & 1 & 1 & 39 & 27 & 14 & 9 \\
\hline Legionellosis & 37 & 104 & 66 & 60 & 75 & 74 & 33 & 46 & 41 & 41 & 68 & 44 & 60 & 80 & 89 & 77 \\
\hline L. longbeachae & 0 & 14 & 13 & 8 & 16 & 30 & 9 & 19 & 12 & 12 & 29 & 21 & 37 & 27 & 24 & 22 \\
\hline L.pneumophilab & 16 & 80 & 34 & 30 & 35 & 34 & 18 & 22 & 22 & 26 & 38 & 22 & 23 & 51 & 64 & 54 \\
\hline Legionnaires' disease - other & 21 & 10 & 19 & 22 & 24 & 10 & 6 & 5 & 7 & 3 & 1 & 1 & 0 & 2 & 1 & 1 \\
\hline Leprosy & 1 & 7 & 5 & 3 & 3 & 2 & 0 & 0 & 1 & 2 & 4 & 0 & 2 & 5 & 1 & 1 \\
\hline Leptospirosis $^{b}$ & 28 & 21 & 16 & 14 & 6 & 33 & 33 & 50 & 56 & 54 & 66 & 39 & 39 & 40 & 35 & 17 \\
\hline Listeriosis $^{\mathrm{b}}$ & 11 & 13 & 12 & 10 & 14 & 22 & 23 & 28 & 22 & 18 & 12 & 11 & 28 & 30 & 25 & 26 \\
\hline Lymphogranuloma venereum (LGV)b & 0 & 0 & 0 & 0 & 0 & 0 & 0 & 0 & 0 & 0 & 0 & 0 & 0 & 1 & 2 & 1 \\
\hline Malariab & 171 & 110 & 174 & 184 & 96 & 204 & 173 & 158 & 174 & 232 & 157 & 105 & 120 & 101 & 206 & 140 \\
\hline Measles & 495 & 805 & 2348 & 1484 & 596 & 191 & 273 & 119 & 32 & 36 & 31 & 8 & 18 & 12 & 5 & 60 \\
\hline Measles lab confirm ${ }^{b}$ & 19 & 76 & 460 & 302 & 138 & 35 & 98 & 19 & 13 & 22 & 18 & 6 & 14 & 11 & 4 & 48 \\
\hline Measles (other) & 476 & 729 & 1888 & 1182 & 458 & 156 & 175 & 100 & 19 & 14 & 13 & 2 & 4 & 1 & 1 & 12 \\
\hline Meningococcal disease & 128 & 121 & 153 & 142 & 113 & 161 & 218 & 186 & 221 & 253 & 234 & $21 \overline{6}$ & 202 & 149 & 140 & 107 \\
\hline Meningococcal - Type $\mathrm{B}^{\mathrm{b}}$ & 0 & 3 & 7 & 7 & 23 & 36 & 53 & 55 & 95 & 93 & 90 & 105 & 100 & 81 & 73 & 54 \\
\hline Meningococcal - Type $C^{b}$ & 0 & 4 & 6 & 9 & 8 & 35 & 55 & 55 & 60 & 64 & 38 & 54 & 45 & 24 & 16 & 13 \\
\hline Meningococcal - Type W135 & 0 & 0 & 0 & 0 & 1 & 0 & 2 & 4 & 4 & 4 & 2 & 2 & 2 & 5 & 8 & 5 \\
\hline Meningococcal - Type $\mathrm{Y}^{\mathrm{b}}$ & 0 & 0 & 1 & 1 & 0 & 1 & 0 & 7 & 1 & 7 & 2 & 2 & 5 & 3 & 3 & 1 \\
\hline Meningococcal disease - Other & 128 & 114 & 139 & 125 & 81 & 89 & 108 & 65 & 61 & 85 & 102 & 53 & 50 & 36 & 40 & 34 \\
\hline Mumps $^{b}$ & 8 & 23 & 13 & 11 & 14 & 27 & 29 & 39 & 33 & 92 & 28 & 29 & 35 & 65 & 111 & 154 \\
\hline Paratyphoid ${ }^{b, d}$ & 20 & 8 & 9 & 11 & 12 & 15 & 5 & 9 & 5 & 14 & 11 & 13 & 22 & 10 & 0 & 0 \\
\hline Pertussis & 49 & 217 & 1533 & 1405 & 1369 & 1156 & 4246 & 2309 & 1415 & 3691 & 4437 & 2012 & 2772 & 3567 & 5809 & 4918 \\
\hline Pneumococcal disease (invasive) ${ }^{b}$ & Not no & tifiable & until De & ecembe & 2000 & & & & & & 444 & 861 & 802 & 906 & 641 & 564 \\
\hline Psittacosis ${ }^{b}$ & Not no & tifiable & until De & ecembe & 2000 & & & & & & 38 & 155 & 87 & 81 & 121 & 94 \\
\hline Q feverb & 167 & 213 & 403 & 267 & 201 & 287 & 258 & 236 & 164 & 132 & 144 & 309 & 288 & 223 & 143 & 175 \\
\hline Rubella $^{b}$ & 60 & 324 & 1186 & 233 & 2376 & 636 & 153 & 78 & 46 & 191 & 58 & 35 & 24 & 18 & 10 & 37 \\
\hline Rubella (congenital) b & 1 & 0 & 2 & 4 & 1 & 5 & 0 & 0 & 1 & 0 & 0 & 0 & 1 & 1 & 0 & 0 \\
\hline Rubellab & 59 & 324 & 1184 & 229 & 2375 & 631 & 153 & 78 & 45 & 191 & 58 & 35 & 23 & 17 & 10 & 37 \\
\hline Salmonella infection ${ }^{b, d}$ & 1170 & 802 & 980 & 1101 & 1366 & 1224 & 1698 & 1812 & 1438 & 1399 & 1644 & 2100 & 1839 & 2134 & 2176 & 2058 \\
\hline Shigellosis ${ }^{b}$ & Not no & tifiable & until De & ecembe & 2000 & & & & & & 134 & 85 & 59 & 96 & 135 & 75 \\
\hline Syphilis & 580 & 873 & 730 & 965 & 833 & 662 & 512 & 611 & 585 & 580 & 547 & 646 & 843 & 1042 & 840 & 881 \\
\hline Syphilis infectious ${ }^{b, c}$ & 1 & 3 & 6 & 29 & 132 & 72 & 57 & 45 & 86 & 80 & 67 & 128 & 245 & 302 & 242 & 210 \\
\hline Syphilis congenital & 1 & 1 & 0 & 2 & 6 & 3 & 3 & 0 & 3 & 2 & 1 & 1 & 2 & 1 & 5 & 4 \\
\hline Syphilis otherb & 578 & 869 & 724 & 934 & 695 & 587 & 452 & 566 & 496 & 498 & 479 & 517 & 596 & 739 & 593 & 667 \\
\hline Tetanus & 5 & 2 & 5 & 4 & 0 & 1 & 3 & 3 & 1 & 2 & 0 & 0 & 1 & 1 & 1 & 2 \\
\hline Tuberculosis $^{b}$ & 429 & 394 & 389 & 394 & 443 & 410 & 422 & 382 & 483 & 448 & 416 & 447 & 386 & 430 & 449 & 461 \\
\hline Typhoid $^{b}$ & 38 & 20 & 28 & 25 & 27 & 30 & 28 & 18 & 32 & 28 & 32 & 26 & 16 & 39 & 28 & 35 \\
\hline Verotoxigenic Escherichia coli infection b & Not no & tifiable & until De & ecembe & $r 1996$ & & & 2 & 0 & 1 & 1 & 6 & 3 & 5 & 16 & 10 \\
\hline
\end{tabular}

ayear of onset: the earlier of patient-reported onset date, specimen date or date of notification.

bLaboratory-confirmed cases only.

Includes Syphilis primary, Syphilis secondary, Syphilis $<1$ year duration and Syphilis newly acquired.

dFrom 2005, all paratyphoid recorded as salmonellosis.

eFoodborne illness cases are only those notified as part of an outbreak.

NOS: not otherwise specified.

No case of the following diseases have been notified since 1991: Diphtheria ${ }^{b}$, Granuloma inguinale $^{b}$, Lymphogranuloma venereum ${ }^{b}$, Plague ${ }^{b}$, Poliomyelitis $^{b}$, Rabies, Typhus ${ }^{b}$, Viral haemorrhagic fever, Yellow fever. 
Table 2. Disease notifications by month of onset of illness ${ }^{\mathrm{a}}$, NSW, 2006

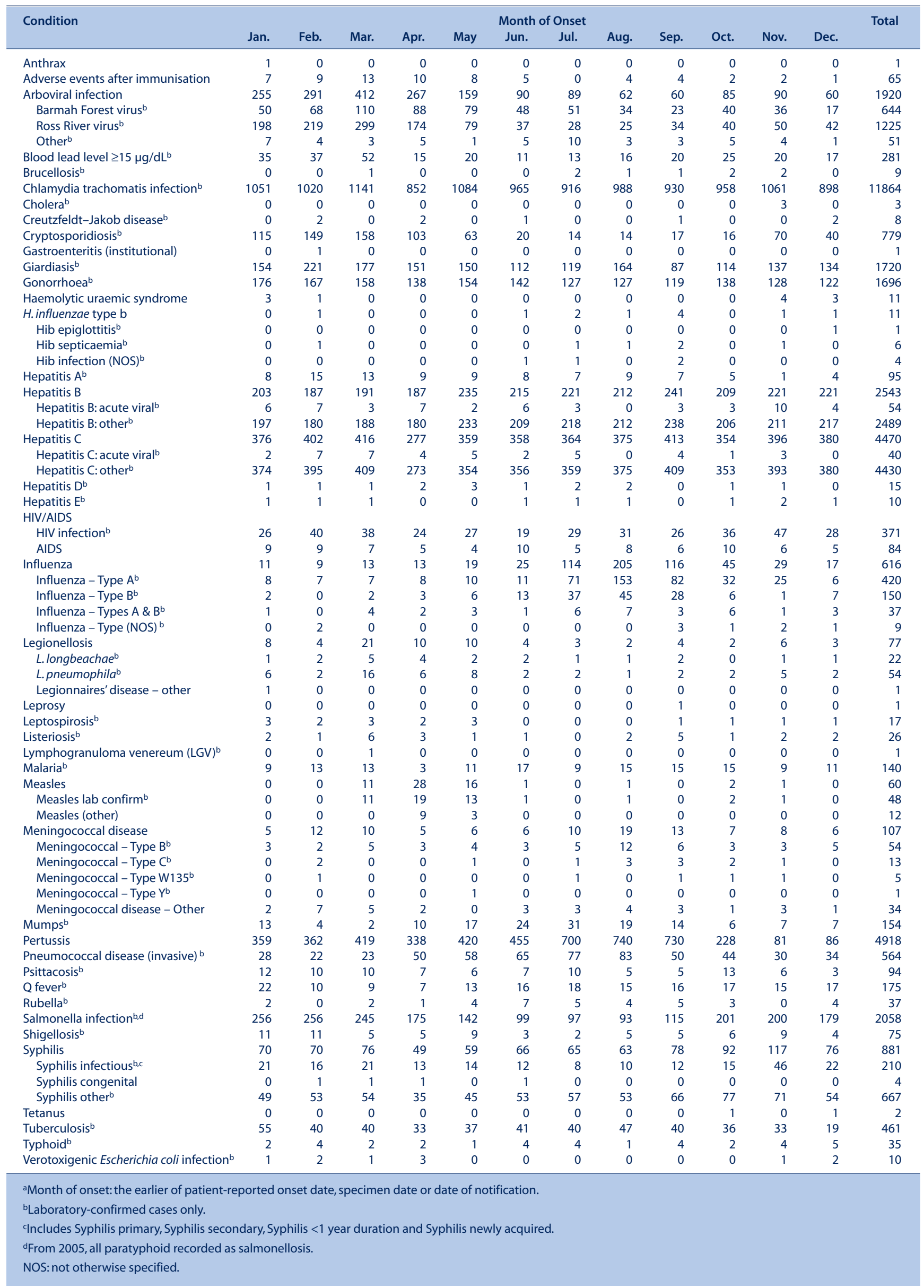




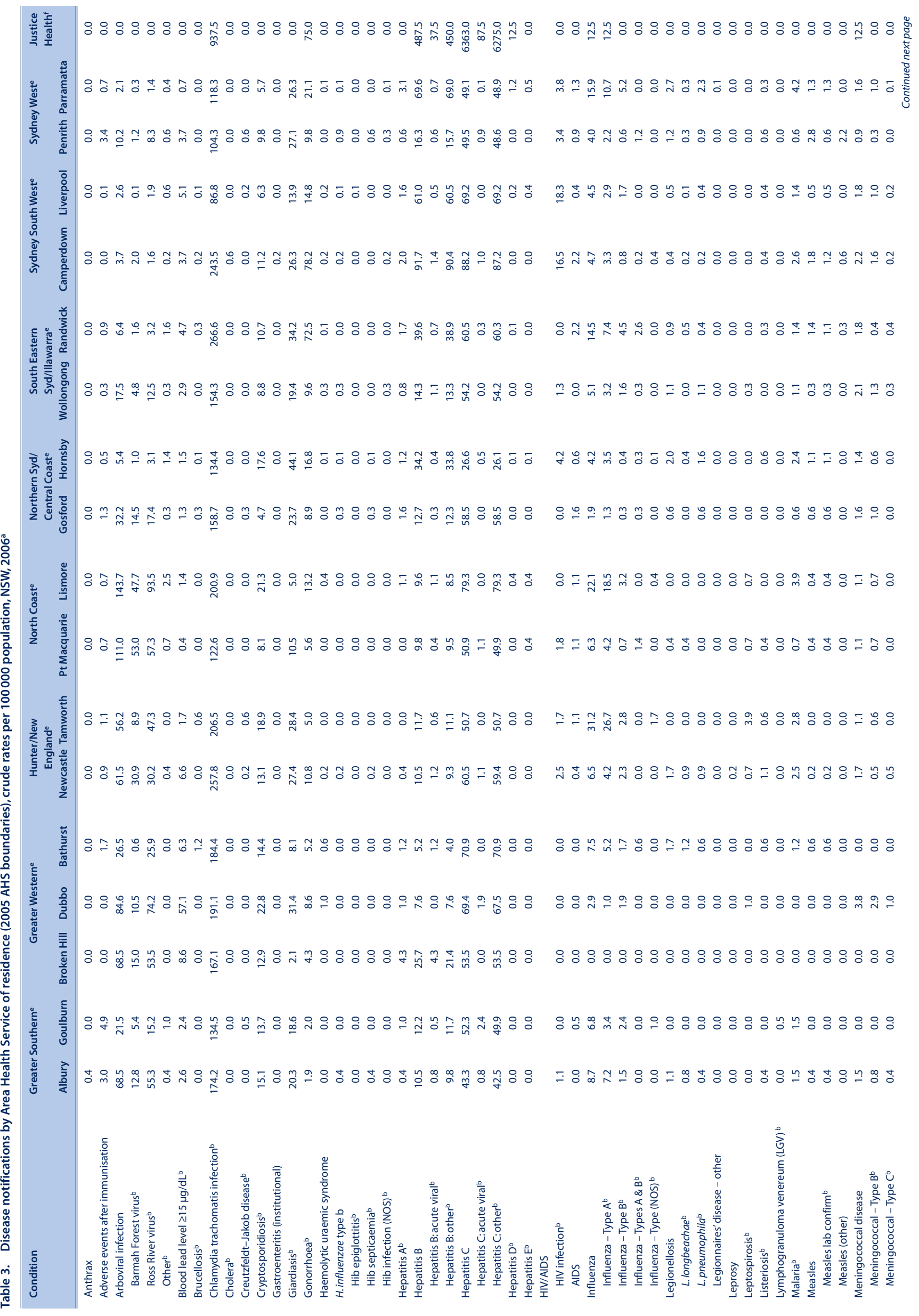




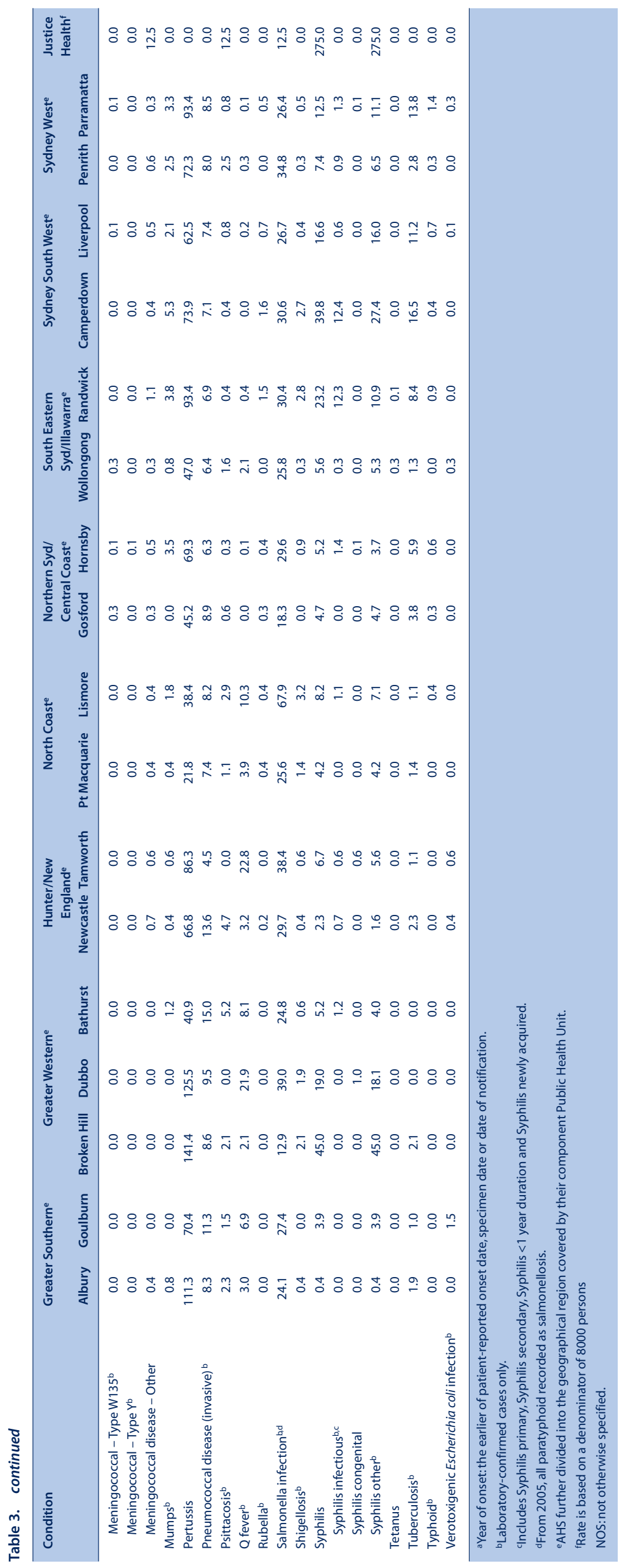




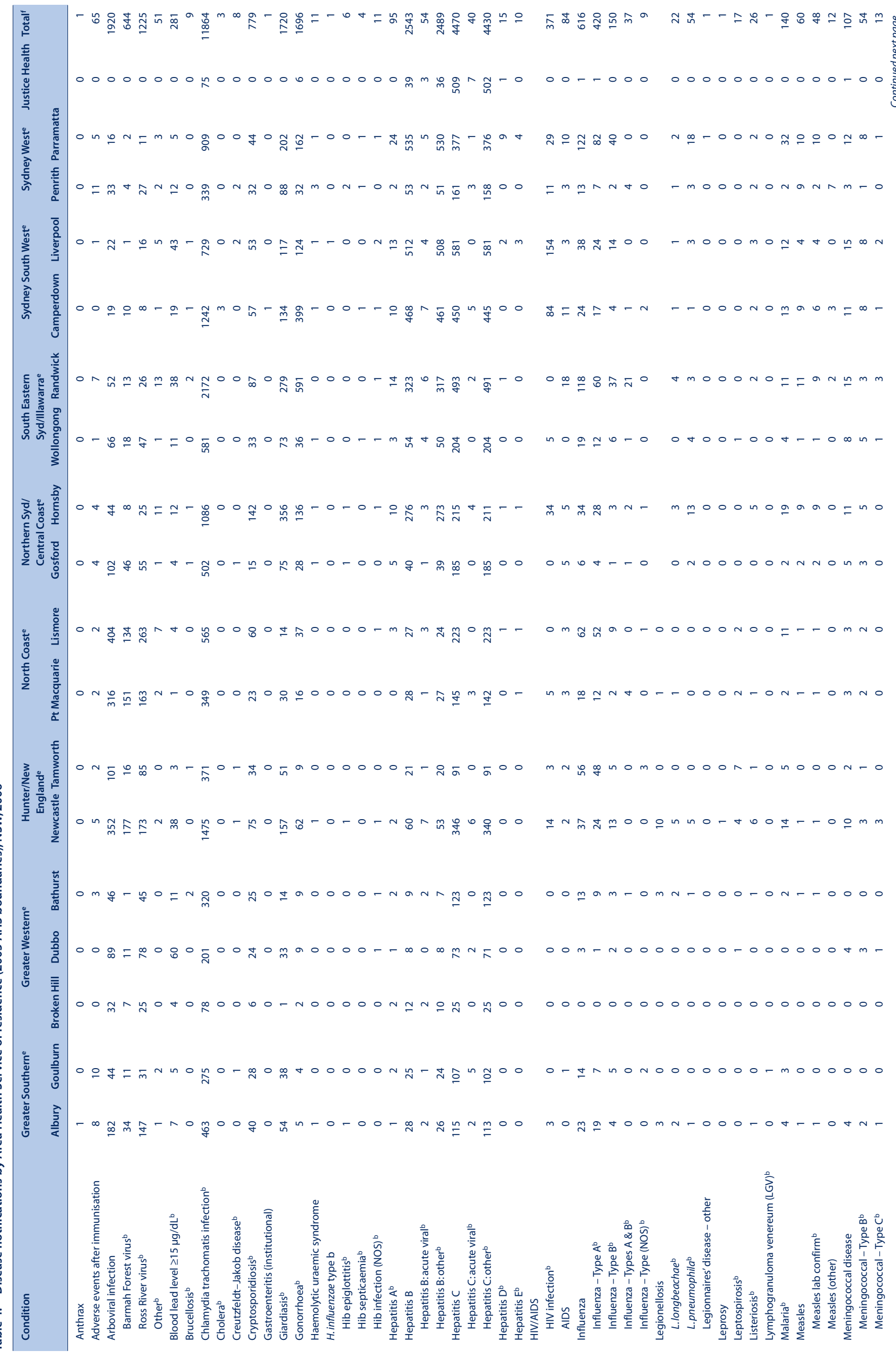




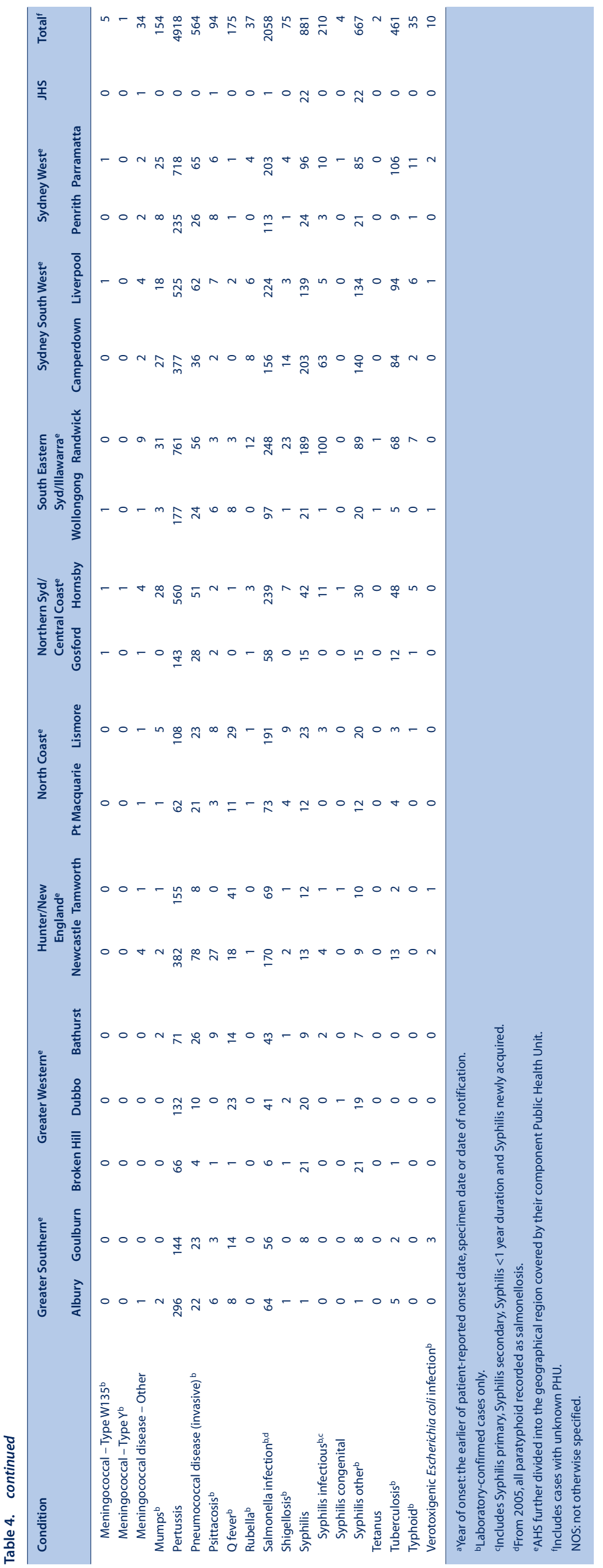


Table 5. Disease notifications by age group and sex of the case, NSW, 2006

\begin{tabular}{|c|c|c|c|c|c|c|c|c|c|c|c|c|c|}
\hline \multirow[t]{2}{*}{ Condition } & \multicolumn{2}{|c|}{$0-4$ years } & \multicolumn{2}{|c|}{$5-24$ years } & 25 & 4 yrs & $45-6$ & years & $65+$ & lears & & & Total $^{\mathrm{e}}$ \\
\hline & $\mathbf{F}$ & M & $\mathbf{F}$ & M & $\mathrm{F}$ & $M$ & $\mathrm{~F}$ & M & $\mathbf{F}$ & M & $\mathbf{F}$ & M & \\
\hline Anthrax & 0 & 0 & 0 & 0 & 0 & 0 & 0 & 1 & 0 & 0 & 0 & 1 & 1 \\
\hline Adverse events after immunisation & 12 & 17 & 8 & 5 & 5 & 0 & 10 & 5 & 3 & 0 & 38 & 27 & 65 \\
\hline Arboviral infection & 2 & 5 & 111 & 101 & 371 & 361 & 374 & 391 & 97 & 105 & 955 & 963 & 1920 \\
\hline Barmah Forest virus ${ }^{b}$ & 1 & 2 & 54 & 32 & 141 & 110 & 131 & 112 & 30 & 31 & 357 & 287 & 644 \\
\hline Ross River virus ${ }^{\mathrm{b}}$ & 1 & 3 & 54 & 61 & 223 & 243 & 231 & 270 & 65 & 72 & 574 & 649 & 1225 \\
\hline Other ${ }^{\mathrm{b}}$ & 0 & 0 & 3 & 8 & 7 & 8 & 12 & 9 & 2 & 2 & 24 & 27 & 51 \\
\hline Blood lead level $\geq 15 \mu \mathrm{g} / \mathrm{dL}^{\mathrm{b}}$ & 6 & 6 & 1 & 37 & 4 & 140 & 2 & 72 & 1 & 11 & 14 & 266 & 281 \\
\hline Brucellosis $^{b}$ & 0 & 0 & 1 & 1 & 0 & 2 & 0 & 4 & 0 & 1 & 1 & 8 & 9 \\
\hline Chlamydia trachomatis infection ${ }^{b}$ & 31 & 22 & 4563 & 2077 & 2101 & 2552 & 113 & 366 & 5 & 14 & 6814 & 5031 & 11864 \\
\hline Cholera $^{b}$ & 0 & 0 & 0 & 0 & 0 & 0 & 0 & 0 & 3 & 0 & 3 & 0 & 3 \\
\hline Creutzfeldt-Jakob disease $^{b}$ & 0 & 0 & 0 & 0 & 0 & 0 & 2 & 0 & 2 & 4 & 4 & 4 & 8 \\
\hline Cryptosporidiosis $^{\mathrm{b}}$ & 144 & 190 & 98 & 102 & 139 & 57 & 20 & 11 & 12 & 2 & 413 & 362 & 779 \\
\hline Giardiasis $^{\mathrm{b}}$ & 193 & 263 & 138 & 179 & 298 & 282 & 148 & 109 & 63 & 44 & 840 & 877 & 1720 \\
\hline Gonorrhoea $^{b}$ & 2 & 0 & 109 & 340 & 99 & 930 & 16 & 189 & 1 & 5 & 227 & 1464 & 1696 \\
\hline Haemolytic uraemic syndrome & 3 & 2 & 1 & 3 & 1 & 0 & 1 & 0 & 0 & 0 & 6 & 5 & 11 \\
\hline H. influenzae type $b$ & 2 & 2 & 0 & 0 & 2 & 0 & 0 & 0 & 3 & 2 & 7 & 4 & 11 \\
\hline Hib epiglottitis ${ }^{b}$ & 0 & 0 & 0 & 0 & 0 & 0 & 0 & 0 & 0 & 1 & 0 & 1 & 1 \\
\hline Hib septicaemiab & 0 & 2 & 0 & 0 & 1 & 0 & 0 & 0 & 2 & 1 & 3 & 3 & 6 \\
\hline Hib infection (NOS) ${ }^{b}$ & 2 & 0 & 0 & 0 & 1 & 0 & 0 & 0 & 1 & 0 & 4 & 0 & 4 \\
\hline Hepatitis $A^{b}$ & 5 & 2 & 21 & 19 & 14 & 13 & 7 & 5 & 3 & 6 & 50 & 45 & 95 \\
\hline Hepatitis B & 5 & 9 & 190 & 221 & 645 & 728 & 248 & 377 & 33 & 63 & 1121 & 1399 & 2543 \\
\hline Hepatitis B: acute viral ${ }^{b}$ & 0 & 3 & 7 & 7 & 11 & 17 & 4 & 4 & 0 & 0 & 22 & 31 & 54 \\
\hline Hepatitis B: other ${ }^{b}$ & 5 & 6 & 183 & 214 & 634 & 711 & 244 & 373 & 33 & 63 & 1099 & 1368 & 2489 \\
\hline Hepatitis C & 7 & 10 & 254 & 313 & 925 & 1539 & 386 & 842 & 78 & 77 & 1650 & 2781 & 4470 \\
\hline Hepatitis C: acute viral ${ }^{b}$ & 0 & 1 & 5 & 6 & 8 & 13 & 2 & 4 & 0 & 1 & 15 & 25 & 40 \\
\hline Hepatitis C: other ${ }^{b}$ & 7 & 9 & 249 & 307 & 917 & 1526 & 384 & 838 & 78 & 76 & 1635 & 2756 & 4430 \\
\hline Hepatitis $D^{b}$ & 0 & 0 & 1 & 2 & 3 & 5 & 1 & 3 & 0 & 0 & 5 & 10 & 15 \\
\hline Hepatitis $E^{b}$ & 0 & 0 & 4 & 2 & 1 & 3 & 0 & 0 & 0 & 0 & 5 & 5 & 10 \\
\hline HIV/AIDS & & & & & & & & & & & & & \\
\hline HIV infection ${ }^{b}$ & 1 & 1 & 9 & 23 & 30 & 214 & 7 & 80 & 0 & 4 & 47 & 322 & 371 \\
\hline AIDS & 0 & 0 & 0 & 0 & 5 & 47 & 2 & 29 & 0 & 1 & 7 & 77 & 84 \\
\hline Influenza & 67 & 63 & 64 & 73 & 65 & 50 & 67 & 49 & 61 & 57 & 324 & 292 & 616 \\
\hline Influenza - Type $\mathrm{A}^{\mathrm{b}}$ & 46 & 46 & 36 & 46 & 44 & 35 & 47 & 43 & 44 & 33 & 217 & 203 & 420 \\
\hline Influenza - Type $\mathrm{B}^{\mathrm{b}}$ & 18 & 15 & 23 & 26 & 13 & 10 & 11 & 5 & 12 & 17 & 77 & 73 & 150 \\
\hline Influenza - Types A \& B & 1 & 1 & 5 & 1 & 6 & 5 & 7 & 1 & 5 & 5 & 24 & 13 & 37 \\
\hline Influenza - Type (NOS) b & 2 & 1 & 0 & 0 & 2 & 0 & 2 & 0 & 0 & 2 & 6 & 3 & 9 \\
\hline Legionellosis & 0 & 0 & 0 & 0 & 3 & 5 & 12 & 22 & 12 & 23 & 27 & 50 & 77 \\
\hline L. longbeachae b & 0 & 0 & 0 & 0 & 1 & 1 & 6 & 3 & 3 & 8 & 10 & 12 & 22 \\
\hline L.pneumophilab & 0 & 0 & 0 & 0 & 2 & 4 & 6 & 19 & 9 & 14 & 17 & 37 & 54 \\
\hline Legionnaires' disease - other & 0 & 0 & 0 & 0 & 0 & 0 & 0 & 0 & 0 & 1 & 0 & 1 & 1 \\
\hline Leprosy & 0 & 0 & 0 & 0 & 0 & 1 & 0 & 0 & 0 & 0 & 0 & 1 & 1 \\
\hline Leptospirosis $^{b}$ & 0 & 0 & 1 & 2 & 2 & 7 & 0 & 4 & 0 & 1 & 3 & 14 & 17 \\
\hline Listeriosis ${ }^{\mathrm{b}}$ & 0 & 1 & 0 & 0 & 3 & 0 & 2 & 0 & 7 & 13 & 12 & 14 & 26 \\
\hline Lymphogranuloma venereum (LGV)b & 0 & 0 & 0 & 0 & 0 & 0 & 0 & 1 & 0 & 0 & 0 & 1 & 1 \\
\hline Malaria ${ }^{\mathrm{b}}$ & 3 & 5 & 11 & 37 & 12 & 35 & 13 & 19 & 0 & 4 & 39 & 100 & 140 \\
\hline Measles & 8 & 13 & 16 & 4 & 11 & 5 & 1 & 2 & 0 & 0 & 36 & 24 & 60 \\
\hline Measles lab confirmb & 7 & 10 & 12 & 2 & 10 & 4 & 1 & 2 & 0 & 0 & 30 & 18 & 48 \\
\hline Measles (other) & 1 & 3 & 4 & 2 & 1 & 1 & 0 & 0 & 0 & 0 & 6 & 6 & 12 \\
\hline Meningococcal disease & 15 & 19 & 21 & 17 & 12 & 8 & 8 & 3 & 3 & 1 & 59 & 48 & 107 \\
\hline Meningococcal - Type $\mathrm{B}^{\mathrm{b}}$ & 9 & 14 & 11 & 7 & 2 & 3 & 4 & 3 & 1 & 0 & 27 & 27 & 54 \\
\hline Meningococcal - Type $C^{b}$ & 0 & 1 & 4 & 4 & 2 & 0 & 1 & 0 & 1 & 0 & 8 & 5 & 13 \\
\hline Meningococcal - Type W135 b & 1 & 0 & 1 & 0 & 0 & 0 & 2 & 0 & 1 & 0 & 5 & 0 & 5 \\
\hline Meningococcal - Type $Y^{\mathrm{b}}$ & 0 & 0 & 0 & 1 & 0 & 0 & 0 & 0 & 0 & 0 & 0 & 1 & 1 \\
\hline Meningococcal disease - Other & 5 & 4 & 5 & 5 & 8 & 5 & 1 & 0 & 0 & 1 & 19 & 15 & 34 \\
\hline Mumps ${ }^{\text {b }}$ & 0 & 2 & 23 & 28 & 37 & 43 & 12 & 7 & 2 & 0 & 74 & 80 & 154 \\
\hline Pertussis & 82 & 104 & 325 & 266 & 915 & 517 & 1246 & 678 & 431 & 341 & 3000 & 1906 & 4918 \\
\hline Pneumococcal disease (invasive) ${ }^{\mathrm{b}}$ & 24 & 38 & 14 & 33 & 39 & 52 & 69 & 77 & 101 & 117 & 247 & 317 & 564 \\
\hline Psittacosis ${ }^{\mathrm{b}}$ & 0 & 1 & 6 & 3 & 10 & 13 & 16 & 22 & 6 & 17 & 38 & 56 & 94 \\
\hline Q feverb & 1 & 1 & 8 & 13 & 15 & 49 & 17 & 50 & 5 & 16 & 46 & 129 & 175 \\
\hline Rubellab & 1 & 1 & 2 & 5 & 10 & 14 & 1 & 1 & 1 & 0 & 15 & 21 & 37 \\
\hline Salmonella infection ${ }^{\mathrm{b}, \mathrm{d}}$ & 272 & 278 & 271 & 308 & 195 & 203 & 163 & 151 & 132 & 78 & 1033 & 1019 & 2058 \\
\hline Shigellosis ${ }^{b}$ & 5 & 5 & 8 & 9 & 11 & 21 & 6 & 5 & 1 & 4 & 31 & 44 & 75 \\
\hline Syphilis & 1 & 3 & 22 & 34 & 128 & 305 & 44 & 170 & 52 & 119 & 247 & 631 & 881 \\
\hline Syphilis infectious ${ }^{\mathrm{b}, \mathrm{c}}$ & 0 & 0 & 3 & 17 & 14 & 131 & 2 & 39 & 0 & 3 & 19 & 190 & 210 \\
\hline Syphilis congenital & 1 & 3 & 0 & 0 & 0 & 0 & 0 & 0 & 0 & 0 & 1 & 3 & 4 \\
\hline Syphilis other ${ }^{\mathrm{b}}$ & 0 & 0 & 19 & 17 & 114 & 174 & 42 & 131 & 52 & 116 & 227 & 438 & 667 \\
\hline Tetanus & 0 & 0 & 0 & 0 & 0 & 0 & 0 & 0 & 1 & 1 & 1 & 1 & 2 \\
\hline Tuberculosis $^{b}$ & 5 & 2 & 28 & 38 & 88 & 79 & 54 & 63 & 39 & 64 & 214 & 246 & 461 \\
\hline Typhoidb & 4 & 1 & 4 & 6 & 6 & 11 & 1 & 1 & 0 & 1 & 15 & 20 & 35 \\
\hline Verotoxigenic Escherichia coli infection ${ }^{b}$ & 0 & 1 & 1 & 2 & 0 & 1 & 2 & 1 & 1 & 1 & 4 & 6 & 10 \\
\hline & & & & & & & & & & & & & \\
\hline $\begin{array}{l}\text { Anset: the earlier of patient-reported on } \\
\text { 'Laboratory-confirmed cases only. }\end{array}$ & & & 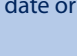 & 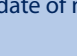 & & & & & & & & & \\
\hline Includes Syphilis primary, Syphilis secon & Jary, S) & $1 \mid 15<<$ & r dura & on and & ohilis n & y acq & & & & & & & \\
\hline dFrom 2005 , all paratyphoid recorded as & almon & osis. & & & & & & & & & & & \\
\hline eIncludes cases with unknown age and s & $x$ and & eople & identif & as trar & nder. & & & & & & & & \\
\hline NOS: not otherwise specified. F: female. N & . & & & & & & & & & & & & \\
\hline
\end{tabular}


Table 6. Disease notifications where the case had died at the time of public health follow-up, by year of onset of illness ${ }^{\mathrm{a}}$, NSW, 1991-2006

\begin{tabular}{|c|c|c|c|c|c|c|c|c|c|c|c|c|c|c|c|c|}
\hline Condition & 1991 & 1992 & 1993 & 1994 & 1995 & 1996 & 1997 & 1998 & 1999 & 2000 & 2001 & 2002 & 2003 & 2004 & 2005 & 2006 \\
\hline Haemolytic uraemic syndrome & 0 & 0 & 0 & 0 & 0 & 0 & 0 & 0 & 1 & 1 & 0 & 1 & 0 & 1 & 1 & 1 \\
\hline Hepatitis $A^{b}$ & 2 & 1 & 0 & 0 & 0 & 0 & 1 & 2 & 0 & 0 & 0 & 1 & 0 & 0 & 0 & 0 \\
\hline H. influenzae type b & 4 & 4 & 4 & 1 & 0 & 2 & 0 & 0 & 0 & 1 & 1 & 0 & 0 & 0 & 0 & 2 \\
\hline HIV/AIDS deathsc & 350 & 337 & 393 & 432 & 365 & 280 & 134 & 76 & 74 & 87 & 62 & 67 & 64 & 58 & 38 & 36 \\
\hline Legionnaires' disease - L.pneumophilab & 1 & 10 & 5 & 3 & 4 & 6 & 2 & 0 & 2 & 1 & 2 & 0 & 2 & 2 & 2 & 1 \\
\hline Measles & 3 & 2 & 0 & 0 & 0 & 0 & 0 & 0 & 0 & 0 & 0 & 0 & 0 & 0 & 0 & 1 \\
\hline Meningococcal disease - Type $\mathrm{B}^{\mathrm{b}}$ & 0 & 0 & 1 & 1 & 3 & 0 & 4 & 2 & 7 & 6 & 2 & 8 & 6 & 4 & 4 & 4 \\
\hline Meningococcal disease - Type $C^{b}$ & 0 & 0 & 1 & 1 & 0 & 2 & 2 & 10 & 4 & 4 & 5 & 10 & 6 & 1 & 2 & 1 \\
\hline Meningococcal disease - Type W135b & 0 & 0 & 0 & 0 & 0 & 0 & 0 & 0 & 1 & 0 & 0 & 0 & 0 & 0 & 2 & 1 \\
\hline Meningococcal disease - Type $\mathrm{Y}^{\mathrm{b}}$ & 0 & 0 & 0 & 0 & 0 & 0 & 0 & 1 & 0 & 1 & 0 & 0 & 0 & 0 & 1 & 0 \\
\hline Meningococcal disease - Other & 3 & 8 & 9 & 13 & 4 & 5 & 1 & 4 & 2 & 3 & 0 & 1 & 2 & 1 & 0 & 0 \\
\hline Meningococcal (total) & 3 & 8 & 11 & 15 & 7 & 7 & 7 & 17 & 14 & 14 & 7 & 19 & 14 & 6 & 9 & 6 \\
\hline Pneumococcal disease (invasive) ${ }^{b}$ & 0 & 0 & 0 & 0 & 0 & 0 & 0 & 0 & 0 & 0 & 6 & 96 & 75 & 89 & 61 & 61 \\
\hline Tetanus & 0 & 0 & 1 & 0 & 0 & 0 & 0 & 0 & 0 & 0 & 0 & 0 & 0 & 0 & 0 & 0 \\
\hline Tuberculosis ${ }^{b}$ & 10 & 26 & 31 & 25 & 23 & 16 & 21 & 25 & 29 & 40 & 33 & 39 & 22 & 28 & 22 & 27 \\
\hline Verotoxigenic Escherichia coli infections ${ }^{b}$ & 0 & 0 & 0 & 0 & 0 & 0 & 0 & 0 & 0 & 0 & 0 & 0 & 0 & 0 & 1 & 0 \\
\hline \multicolumn{17}{|c|}{ ayear of onset: the earlier of patient reported onset date, specimen date or date of notification. } \\
\hline
\end{tabular}




\section{Enhanced surveillance of hepatitis B infection in inner-western Sydney}

\author{
Bradley L. Forssman ${ }^{\mathrm{A}, \mathrm{B}}$ and Leena Gupta ${ }^{\mathrm{A}}$ \\ ASydney South West Area Health Service Public Health Unit, \\ Sydney South West Area Health Service \\ ${ }^{\mathrm{B} C o r r e s p o n d i n g}$ author. Email: bforssman@optusnet.com.au
}

\begin{abstract}
Objectives: We developed an enhanced surveillance system for hepatitis B to improve the detection of newly acquired cases and to collect epidemiological data. Methods: The study was undertaken from February to June (inclusive) 2005 at the Sydney South West Area Health Service Eastern Zone Public Health Unit. A letter was sent to treating doctors on receipt of a notification, requesting additional information on cases. Cases identified by the treating doctors as newly acquired were followed up by telephone. Results: There were 295 notifications of hepatitis B in the period, of which three were newly acquired infections. Only one of these three cases was identified through enhanced surveillance. Information on ethnicity was obtained. Conclusions: This enhanced surveillance system is of limited value as an ongoing process. We recommend that it be undertaken periodically to monitor the epidemiology of the disease.
\end{abstract}

Hepatitis B is a viral infection that can cause chronic inflammation of the liver and may lead to cirrhosis and hepatocellular carcinoma. ${ }^{1}$ In Australia in 2005, 6793 unspecified hepatitis B notifications were reported to the National Notifiable Disease Surveillance System, with 235 of these reported as being incident (or newly acquired) cases. $^{2}$ In NSW, there were 54 newly acquired cases reported. ${ }^{2}$ Furthermore, it has been estimated that the prevalence of chronic hepatitis B infection in Australia ranges from $0.47-0.87 \%{ }^{3}$ Hepatitis $\mathrm{B}$ is preventable by vaccination, and further spread can be avoided through administration of immunoglobulin prophylaxis within 14 days of exposure, ${ }^{1}$ as well as through the provision of information about modes of transmission and infection control. In addition, new treatment modalities are proving to be effective. ${ }^{4}$ It would therefore be beneficial for cases of newly acquired hepatitis B to be detected in a timely manner to allow effective public health action to be instituted, as well as to facilitate early referral for management.

Identifying newly acquired cases of hepatitis B can be problematic, however, as laboratories usually only test and report results for positive surface antigen (HBsAg), which indicates unspecified infection with hepatitis $\mathrm{B}$, rather than IgM antibody to core antigen ( $\mathrm{HBcAb} \operatorname{IgM})$, which indicates newly acquired infection. In addition, clinical details or related results such as liver function tests are very rarely provided to the Public Health Unit (PHU). Identification of newly acquired cases is therefore highly dependent on the treating doctor notifying the PHU. While medical practitioners are required under the NSW Public Health Act 1991 to notify acute episodes of viral hepatitis, it is acknowledged that under-reporting is a significant issue., 5 In addition, laboratories provide limited demographic data (age, sex and postcode only), resulting in an incomplete picture of the epidemiology of hepatitis B.

A recent report of an enhanced surveillance system for hepatitis B in south-eastern Sydney stated that it was effective in increasing the detection of newly acquired cases by three-fold (from three to 10 cases) over a sixmonth period. ${ }^{7}$ However, this system required a reasonably high staff workload and relied on access to supplementary investigation results and clinical details. Consequently, it was unsuitable for implementation at our centre. An alternative enhanced surveillance system for hepatitis B infection was therefore developed, with the aims of improving both the detection of newly acquired cases and the collection of epidemiological data to inform targeted public health action. This article presents the results of this enhanced surveillance and discusses the implications of its implementation.

\section{Methods}

In NSW, hepatitis B infection is notifiable by laboratories and acute viral hepatitis is notifiable by medical practitioners and hospitals under the Public Health Act 1991. The case definition for newly acquired hepatitis B is provided in Box 1.8

Enhanced surveillance was undertaken from February to June (inclusive) 2005 at the Sydney South West Area Health Service (SSWAHS) Eastern Zone PHU, which services a large, ethnically diverse population of approximately 500000 in inner-western Sydney. ${ }^{9}$ After receipt of 
Box 1. Case definition for newly acquired hepatitis B infection ${ }^{8}$

- Detection of HBsAg in a patient shown to be negative within the last 24 months, or

- Detection of HBsAg and IgM to hepatitis B core antigen, in the absence of prior evidence of HBV infection, or

- Detection of HBV by nucleic acid testing, and IgM to hepatitis $B$ core antigen, in the absence of prior evidence of HBV infection.

Source: Notifiable Diseases Manual, NSW Department of Health 2004

a laboratory notification of HBsAg, a letter and two-page questionnaire were mailed to the medical practitioner who requested the test. Due to limited human resources, a reminder letter was not sent to treating doctors who did not respond. The letter outlined the reasons for undertaking this enhanced surveillance. The first page of the questionnaire requested demographic details of the case (gender, occupation, country of birth, language spoken at home, and Aboriginal and Torres Strait Islander status), and after providing the case definition of a newly acquired case of hepatitis $\mathrm{B}$, it requested the practitioner's opinion as to whether this case of hepatitis B was newly acquired. In addition, information regarding household or sexual contacts and the use of hepatitis B vaccine for these contacts was requested, as well as asking if the medical practitioner required further information regarding hepatitis $\mathrm{B}$, either for their patients or to assist with tertiary referrals.

If the case was considered newly acquired, the medical practitioner was asked to complete the second page of the questionnaire. This requested information regarding the presence and onset date of symptoms, and possible risk exposures. If further information was required for public health follow-up, it was obtained by telephoning the medical practitioner and the patient.

Data from returned questionnaires were entered into the NSW Health Notifiable Diseases Database and into a separate database created in Microsoft Excel 2000, and frequencies of selected characteristics were calculated.

In addition to the laboratory notifications of HBsAg, the PHU also received telephone notifications of acute hepatitis B directly from medical practitioners. The surveillance officers then obtained demographic and risk factor information regarding these cases from the medical practitioner and, if permission was given, directly from the patient. These cases were considered to be the 'baseline' number of notifications that would occur if the enhanced surveillance system was not in place.

The cost to the PHU of implementing this enhanced surveillance system was calculated by recording the amount of staff time taken for data entry, questionnaire and letter preparation and mail out, and telephone follow-up with treating doctors.

\section{Results}

\section{Enhanced surveillance}

There were 295 notifications of hepatitis B in the period February to July 2005 (average monthly notification rate of 9.9 per 100000 people). Median time taken to send questionnaires to treating doctors was 11 days from receipt of the laboratory notification (range 1-36 days). Three notifications were confirmed cases of newly acquired hepatitis B. Two of these were notified directly to the PHU by the treating medical practitioner, and the remaining case was detected as a result of the enhanced surveillance. There were eight additional cases that medical practitioners indicated on the questionnaire were newly acquired, but after follow-up by telephone it was determined that these cases did not meet the case definition for a newly acquired case. Out of the 293 laboratory notifications, 204 questionnaires were returned (response rate 69.6\%).

There were 104 cases (51\%) that had household contacts. Of these cases, it was indicated by medical practitioners that for 67 (64.4\%), hepatitis B vaccination had been instituted for their contacts.

Less than a quarter of medical practitioners requested further information regarding hepatitis $\mathrm{B}$, either for the information of their patients $(n=48,23.1 \%)$ or to assist in tertiary referral $(n=43,21.1 \%)$.

The additional staff time that this enhanced surveillance required was estimated to be four hours per week. If a public health nurse (5th year) were employed to perform these duties, the additional cost to the PHU would be approximately $\$ 85$ per week, or $\$ 4500$ per year. ${ }^{10}$ If, however, an existing public health surveillance officer were used to carry out this surveillance, this would likely be at the expense of an alternative communicable disease control activity.

\section{Demographics of cases}

The demographic characteristics of these cases are shown in Table 1 and country of birth data are shown in Figure 1. Cases were predominantly male (56\%) and aged 20-40 years. The majority of cases notified to the PHU spoke a language other than English at home (66\%) with 31\% speaking a Chinese dialect. Cases also tended to be born overseas, primarily in China (28\%) and Vietnam (21\%).

In all three cases of newly acquired hepatitis B, risk exposures were both unprotected sexual contact and intravenous drug use. These three people were all born in Australia, two were male and all were aged less than 30 years. 
Table 1. Demographic characteristics of people notified with hepatitis B, Sydney South West Area Health Service (Eastern Zone), NSW, February to July $2005(n=204)$

\begin{tabular}{llrr}
\hline Characteristic & & $\boldsymbol{n}$ & $\%$ \\
\hline Gender & Male & 114 & 55.9 \\
& Female & 89 & 43.6 \\
& Unknown & 1 & 0.5 \\
Age (years) & Median & 35 & \\
& Range & $7-90$ & \\
Language other than & & 134 & 65.7 \\
English spoken at home & & & \\
\hline
\end{tabular}

\section{Demographics of catchment population}

In the 2001 census, $50.6 \%$ of the PHU catchment population were male. The area is culturally diverse, with almost $40 \%$ of residents born overseas. The most common overseas countries of birth were China (4.2\%), the UK (3.5\%), Italy $(2.9 \%)$, Greece $(2.6 \%)$ and Lebanon $(2.3 \%){ }^{9}$

\section{Discussion}

This enhanced surveillance system was able to increase the detection of cases of newly acquired hepatitis B over a six-month period by one case. It also provided additional information regarding ethnicity that would otherwise not be available. In addition, it was helpful in obtaining some (albeit limited) data regarding the needs of medical practitioners with respect to information regarding hepatitis B, and the extent to which medical practitioners undertake appropriate management of contacts.

Our results differ from those of a recently reported enhanced surveillance system. ${ }^{7}$ This may be due to several reasons. We did not have access to the results of supple-

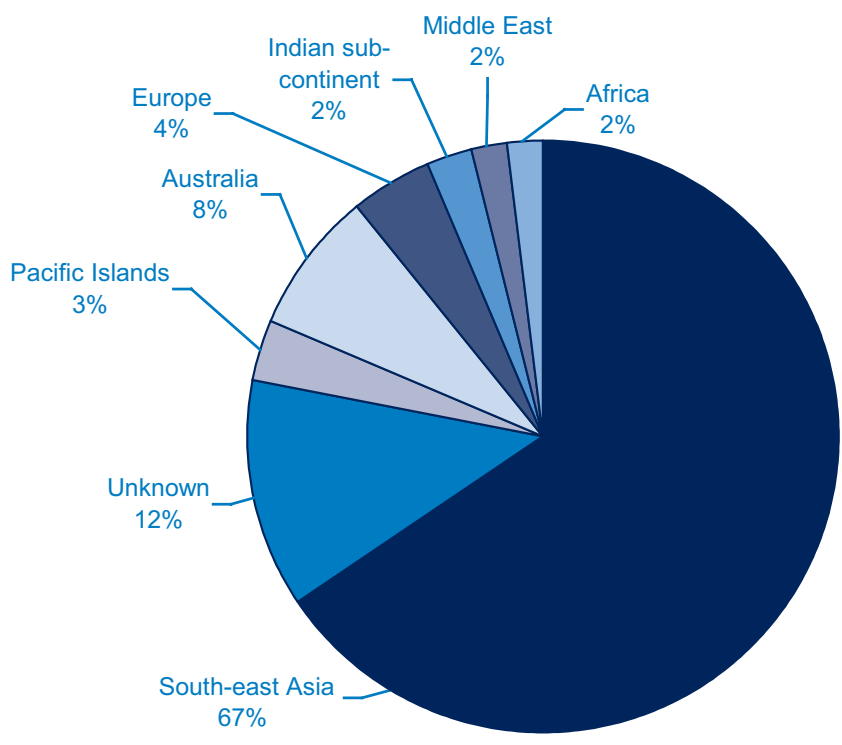

Figure 1. Country of birth of people notified with hepatitis B infection, Sydney South West Area Health Service (Eastern Zone), NSW, February to July $2005(n=204)$ mentary laboratory investigation or clinical details and were therefore unable to predict case classification before contacting treating doctors. This is unlikely to have made a difference to our results, demonstrated by the relatively large numbers of 'false positive' cases. It is possible that the treating doctors in our PHU catchment area do not under-report newly acquired cases of hepatitis B as is widely believed, and therefore enhanced surveillance for this reason is less important.

The inner-western region of Sydney has one of the highest notification rates of hepatitis B in NSW, which has been attributed to the large numbers of residents born in countries where hepatitis B is endemic. ${ }^{11}$ This is reflected in these results, where, compared with the demographic profile of the catchment population, a disproportionately high number of people notified with hepatitis B were born overseas, particularly in South-east Asia where hepatitis B carriage rates have been estimated to be up to $20 \% .^{12}$

Vaccination of household contacts of people with hepatitis B infection is known to reduce the risk of spread. ${ }^{1}$ Vaccination had been commenced in almost two-thirds of cases with household contacts, moderately lower than levels found in a previous study in northern Sydney $(88 \%),{ }^{13}$ but greater than studies in the United Kingdom $(38 \%)^{14}$ and the United States (55\%). ${ }^{15}$ Had there been more time between receipt of laboratory notification and mailing out of enhanced surveillance questionnaires, this vaccination rate may have been even higher. There could be other reasons for non-vaccination, however, such as previous vaccination, contraindication to vaccine, the failure of the contact to attend for vaccination, or the attendance of the contact to another provider for vaccination. This information was not collected by this enhanced surveillance, but it would be possible to do so in the future to enable a better understanding of reasons for the nonvaccination of contacts.

Despite the good response rate (which is likely to have been higher if additional human resources were available to send reminder letters to non-responding treating doctors), only one additional case of newly acquired hepatitis B was detected using this enhanced surveillance system, which did enable public health follow-up that would otherwise not have occurred. This was at the cost, however, of additional staff time spent in following up eight other cases that turned out to be 'false positives'. In addition, demographic information including ethnicity and Aboriginality could be collected on all cases of hepatitis $\mathrm{B}$, which assists in the understanding of the epidemiology of this disease, and could be used, in combination with other methods, to estimate the prevalence of hepatitis B. ${ }^{3}$ In the current climate of competing health funds, these benefits need to be weighed against the costs of such a surveillance system (including the time required by the 
treating doctors to complete the questionnaire). We would recommend that an option is to periodically undertake enhanced surveillance for a limited time, for example, six to 12 months every two to three years, to monitor the epidemiology of this disease. This would assist in filling the gap in data on the prevalence and incidence of this significant public health problem and contribute to informed public health practice.

\section{Acknowledgements}

We would like to thank Shamila Phillip for her assistance with data entry, and the medical practitioners who participated in this project.

\section{References}

1. Heymann DL, editor. Control of communicable diseases manual. 18th ed. Washington DC: American Public Health Association, 2004. pp. 253-261.

2. National Notifiable Disease Surveillance System, Population Health Division, Department of Health and Ageing. Available at http://www9.health.gov.au/cda/Source/Rpt_4_sel.cfm [Accessed 6 June 2007].

3. O'Sullivan BG, Gidding HF, Law M, Kaldor JM, Gilbert GL, Dore GJ. Estimates of chronic hepatitis B virus infection in Australia, 2000. Aust N Z J Public Health 2004; 28: 212-6.

4. Fung SK, Lok ASF. Update on viral hepatitis in 2004. Curr Opin Gastroentrol 2005; 21: 300-7. doi:10.1097/01.mog.0000158109.13722.36

5. Ferson MJ. Combined active-passive surveillance of acute hepatitis B. Commun Dis Intell 1995; 19: 258-9.

6. Alter MJ, Mares A, Hadler SC, Maynard JE. The effect of underreporting on the apparent incidence and epidemiology of acute viral hepatitis. Am J Epidemiol 1987; 125: 133-9.
7. Poulos RG, Ferson MJ. Enhanced surveillance of acute hepatitis B in south-eastern Sydney. Commun Dis Intell 2004; 28: 3 .

8. NSW Health. Hepatitis B response protocol for NSW Public Health Units, Notifiable Diseases Manual. Sydney: NSW Department of Health, 2004.

9. Wen LM, Manson A, Poulos R, Rissel CA. 2001 demographic profile of the Central Sydney Area Health Service. Camperdown: CSAHS Division of Population Health, 2003.

10. Office of Industrial Relations, NSW Department of Commerce. Available at http://www.industrialrelations. nsw.gov.au/awards/index.html [Accessed 6 June 2007].

11. Population Health Division. The health of the people of New South Wales - report of the Chief Health Officer. Sydney: NSW Department of Health. Available at http://www.health.nsw.gov.au/public-health/chorep/com/ com_hepbnot_ahs.htm [Accessed 6 June 2007].

12. Chen C, Wang L, Yu M. Epidemiology of hepatitis B virus infection in the Asia-Pacific region. J Gastro Hepatol. 2000; 15(Supp): E3-6. doi:10.1046/j.1440-1746.2000.02124.x

13. Staff MP, Angel PA. Vaccination among household contacts of chronic hepatitis B carriers by general practitioners. Aust Fam Physician 2002; 31: 491-3.

14. Richardson G, Evans MR, Westmoreland D. Hepatitis B immunisation of household contacts: retrospective study of vaccine coverage. $J$ Epidemiol Community Health 2001; 55: 934-5. doi:10.1136/jech.55.12.934

15. Weinberg MS, Gunn RA, Mast EE, Gresham L, Ginsberg M. Preventing transmission of hepatitis B virus from people with chronic infection. Am J Prev Med 2001; 20: 272-6. doi:10.1016/S0749-3797(01)00298-7 


\section{Prevalence of Mantoux positivity and annual risk of infection for tuberculosis in New South Wales prisoners, 1996 and 2001}

\author{
Michael H. Levy ${ }^{\mathrm{A}, \mathrm{B}}$, Tony G. Butler ${ }^{\mathrm{A}, \mathrm{C}, \mathrm{E}}$ \\ and Jialun Zhou $^{\mathrm{D}}$

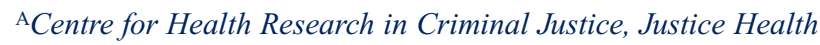 \\ ${ }^{\mathrm{B}}$ School of Public Health, University of Sydney \\ ${ }^{\mathrm{C}}$ National Drug Research Institute, Curtin University \\ of Technology \\ ${ }^{\mathrm{D}}$ National Centre in HIV Epidemiology and Clinical Research, \\ University of New South Wales \\ ECorresponding author. Email: t.butler@curtin.edu.au
}

\begin{abstract}
Objectives: This study compares the prevalence of Mantoux positivity among prisoners in NSW in 1996 and 2001 and examines factors associated with Mycobacterium tuberculosis infection. Design: Cross-sectional random samples of prisoners, including a longitudinal cohort of prisoners screened in both 1996 and 2001. Setting: 29 correctional centres. Participants: 747 men and 167 women participated in the 2001 NSW Inmate Health Survey; a cohort of 104 prisoners from the 1996 and 2001 NSW Inmate Health Surveys. Results: The prevalence of Mantoux positivity remained stable between 1996 and 2001 (12\% and 14\%, $p=0.2)$, and increased among prisoners from Asian backgrounds ( $21 \%$ and $47 \%, p=0.02)$. The annual risk of infection in the cohort among those detained continuously between 1996 and 2001 was 3.1\%, and among recidivists it was $2.7 \%(p=0.6)$. Conclusion: The risk of $M$. tuberculosis infection for Australian prisoners is assessed to be approximately four times higher than that for the community, however there is no attributable risk to the prison environment itself.
\end{abstract}

Tuberculosis is a chronic infection of Mycobacterium tuberculosis which typically occurs in two phases: (1) the initial infection, which often goes unnoticed, and (2) years later, progression to an active disease, which can be infec- tious. Infectious disease is of public health importance as transmission, via the air-borne route, is possible.

International experience has highlighted the role that prisons and prisoners play in community transmission of tuberculosis. Prisons may be important sentinel sites in which to monitor tuberculosis control at a community level. Several studies have highlighted the impact of tuberculosis within correctional centres. ${ }^{1,2}$ The high volume of prisoner movement enhances the potential for the spread of air-borne and droplet-borne illnesses within the correctional setting. ${ }^{3,4}$ There are over 9000 full-time prisoners and periodic detainees in NSW, accounting for around 180000 prisoner movements each year between correctional facilities, courthouses, community visits and hospitals.

Prisons are reported to be a risk for tuberculosis transmission independent of the predisposing risk factors of the prison population. In New York prisons, overcrowding and poor ventilation were reported as independent risk factors. ${ }^{5}$ However, these reports referred to a time and place of poor tuberculosis control in the community.

Given that prisons have many of the risk factors associated with tuberculosis transmission, eg, overcrowding, significant numbers of overseas-born individuals and frequent movement of prisoners, it is essential that this population be continually monitored. Ongoing surveillance will identify changes in the epidemiology of tuberculosis in the NSW prison system and determine changes in the annual risk of infection for the state's prisoner population.

Australia has achieved a sustained high level of tuberculosis control. The 2001 tuberculosis notification rate was 5.1 per 100000 population (being 1.0 per 100000 population for non-Aboriginal Australian born citizens). Australia had a mid-range incarceration rate of 148 prisoners per 100000 adult population in 2001. NSW houses around $35 \%$ of all prisoners in Australia.

The prison environment is implicated as a factor in the epidemiology of tuberculosis, both within the prison and in the general community. There were specific concerns regarding the transmission of tuberculosis within the NSW prison system in $1996,{ }^{6}$ which prompted the inclusion of Mantoux screening in both the 1996 and the 2001 NSW Inmate Health Surveys. ${ }^{7,8}$ 
We examined the prevalence of Mantoux positivity in two cross-sectional surveys of prisoners conducted in NSW, and estimated the annual risk of infection from tuberculosis using a prisoner cohort.

\section{Methods}

A detailed methodology for the Inmate Health Surveys has been previously described. ${ }^{9}$ The cross-sectional surveys involved screening prisoners from all 29 correctional centres in NSW. Participants were randomly selected according to sex, age and Aboriginal status. A random sample of around 10\% full-time men and 34\% full-time women prisoners across the state was taken.

Participants underwent an extensive face-to-face interview covering self-reported physical and mental health (chronic health complaints, disability, recent health complaints and symptoms and traumatic brain injury). In addition, biological samples were taken to screen for a range of infectious diseases (eg, HIV, hepatitis B and hepatitis C) and sexually transmitted infections (eg, chlamydia and gonorrhoea).

Mantoux positivity was measured as a proxy for infection with $M$. tuberculosis. A $0.1-\mathrm{mL}$ solution of purified protein derivative (PPD) (CSL Vaccines, $10 \mathrm{IU}$ ) was administered intracutaneously and the reaction was assessed after 72 hours using the ballpoint pen method. ${ }^{10}$ All prisoners in the samples were offered a Mantoux test.

According to the NSW Health Policy Directive, ${ }^{10}$ Mantoux reactions were considered to be positive if the reaction was:

- $\geq 10 \mathrm{~mm}$ in persons with no previous vaccination history, nor evidence of BCG, or

- $\geq 15 \mathrm{~mm}$ in persons with a previous BCG vaccination history.

Nurses involved in Mantoux testing were recruited from community-based tuberculosis clinics, and were accredited specifically for the performance and interpretation of the Mantoux test. Inmates who were determined to have a positive Mantoux result were recommended for specialist assessment.

The prisoner cohort involved identifying all prisoners who had participated in the 1996 Inmate Health Survey and who were also in detention at the time of the survey in 2001. The Offender Management System ${ }^{11}$ was used to locate these individuals within the NSW correctional system. The Justice Health Human Research and Ethics Committee and the Department of Corrective Services both granted ethics approval for the Inmate Health Surveys.

Assessing the rate of Mantoux positivity per annum and reporting annual risk of infection determined the inci- dence of Mantoux conversion. The International Union of Tuberculosis and Lung Disease Guidelines were used. ${ }^{12}$ The chi-square test was used as appropriate. Forward stepwise logistic regression was used to determine risk factors independently associated with Mantoux positivity. Risk factors entered into the multivariate model were: sex, age, Aboriginality, region of birth, year of survey and history of BCG vaccination. All analyses were conducted using STATA $8.2 .^{13}$

\section{Results}

Cross-sectional surveys (1996 and 2001)

A total of 789 prisoners (657 men and 132 women) were surveyed in 1996 and 914 (747 men and 167 women) in 2001. The response rate was $90 \%$ for the 1996 survey, and $85 \%$ for the 2001 survey. Mantoux tests were performed on $639(81 \%)$ prisoners in 1996 and 803 (88\%) in 2001. The median age of participants who consented to having the Mantoux test was 31 years in 1996 and 30 years in $2001(p=0.04)$. Aboriginal prisoners were younger than non-Aboriginal prisoners in each survey (28 years $v$. 33 years in 1996, $p<0.001 ; 27$ years $v .32$ years in 2001 , $p<0.001)$.

The prevalence of Mantoux positivity remained stable between $1996(12 \%)$ and $2001(14 \%)(p=0.2)$ (Table 1). However, there was an increase in the prevalence of Mantoux positivity among non-Aboriginal prisoners from $11 \%$ in 1996 to $16 \%$ in 2001 ( $p=0.04$ ) and among prisoners reporting Asian countries of birth (21\% in 1996 to $46 \%$ in $2001, p=0.02$ ).

The Mantoux prevalence was similar between the two surveys in 1996 and 2001, after adjusting for sample differences (Table 2). Risk factors independently associated with a positive Mantoux test were Aboriginal status, increasing age and birth outside Australia. In 1996, four prisoners tested positive for antibodies to HIV and one of these prisoners was Mantoux positive. In 2001, one prisoner tested positive for HIV and was Mantoux positive.

No active case of tuberculosis was detected in either crosssectional survey.

\section{Cohort (1996-2001)}

Of the 789 prisoners screened in 1996, 193 were identified as being in detention at the time of the 2001 Inmate Health Survey. Twenty-four percent (48/193) had been detained continuously between the two surveys. One hundred and eighty one $(94 \%)$ prisoners agreed to be rescreened; of these, $104(57 \%)$ received a Mantoux test regardless of their 1996 status (97 negative, seven positive in 1996). (Table 3) A total of 18 of $97(19 \%)$ participants (17 men and one woman) were Mantoux negative in 1996 and positive when retested in 2001. The calculated annual risk of infection was $3.1 \%$. None of the cohort was HIV antibody positive. 
Table 1. Prevalence of Mantoux positivity in NSW prisoners by demographic characteristics and year of survey

\begin{tabular}{|c|c|c|c|c|c|}
\hline & No. tested & $\begin{array}{l}1996 \\
\text { No. Mantoux positive (\%) }\end{array}$ & No. tested & $\begin{array}{l}2001 \\
\text { No. Mantoux positive (\%) }\end{array}$ & $p$-value \\
\hline Total & 639 & $76(12)$ & 803 & 115 (14) & 0.2 \\
\hline \multicolumn{6}{|l|}{ Sex } \\
\hline Male & 536 & $68(13)$ & 654 & $94(14)$ & 0.4 \\
\hline Female & 103 & $8(8)$ & 149 & $21(14)$ & 0.1 \\
\hline$p$-value & & 0.2 & & 0.9 & \\
\hline \multicolumn{6}{|l|}{ Age } \\
\hline$<25$ years & 185 & $9(5)$ & 247 & $17(7)$ & 0.4 \\
\hline $25-40$ years & 262 & $32(12)$ & 340 & $53(16)$ & 0.2 \\
\hline$>40$ years & 191 & $35(18)$ & 216 & $45(21)$ & 0.5 \\
\hline$p$-value & & $<0.001$ & & $<0.001$ & \\
\hline \multicolumn{6}{|l|}{ Aboriginal } \\
\hline No & 450 & $51(11)$ & 578 & $92(16)$ & 0.04 \\
\hline Yes & 189 & $25(13)$ & 225 & $23(10)$ & 0.3 \\
\hline$p$-value & & 0.5 & & 0.04 & \\
\hline \multicolumn{6}{|l|}{ Region of birth } \\
\hline Australia & 501 & $44(9)$ & 638 & $61(10)$ & 0.7 \\
\hline Oceania (other) & 23 & $3(13)$ & 41 & $5(12)$ & 0.9 \\
\hline Asia & 29 & $6(21)$ & 56 & $26(46)$ & 0.02 \\
\hline Europe & 29 & $15(52)$ & 47 & $15(32)$ & 0.09 \\
\hline Other & 18 & $4(22)$ & 17 & $7(41)$ & 0.2 \\
\hline Not reported & 39 & $4(10)$ & 4 & $1(25)$ & 0.4 \\
\hline$p$-value & & $<0.001$ & & $<0.001$ & \\
\hline \multicolumn{6}{|c|}{ Previous BCG vaccination } \\
\hline No & 589 & $65(11)$ & 736 & $101(14)$ & 0.1 \\
\hline Yes & 50 & $11(22)$ & 67 & $14(21)$ & 0.9 \\
\hline$p$-value & & 0.02 & & 0.1 & \\
\hline
\end{tabular}

Source: NSW Inmate Health Surveys, 1996 and 2001

The median age among the Mantoux converters was 34 years (range 24 to 62 years). A similar rate of Mantoux conversion was found between Aboriginal and nonAboriginal participants and among participants of different ages (Table 4). Of the 18 Mantoux converters, 15 (83\%) reported being born in Australia, one in Europe, one in Asia and one had an unknown region of birth. The prevalence of Mantoux converters was similar among participants detained continuously (21\%) and among recidivists (ie, those who had spent some time in the community between surveys) $(16 \%, p=0.6)$.

\section{Discussion}

This report is the first in a randomly selected prisoner cohort and, therefore, the first report of annual risk of infection for tuberculosis in a custodial environment. These data are comparable to those of a survey of police recruits $(11 \%$ of cadets were reported to be Mantoux positive). ${ }^{14}$ Importantly, the results are higher than for community-based surveys of children, but the difference in age group is important to note. ${ }^{15,16}$
We estimate that the annual risk of infection for tuberculosis is approximately four times that for the general community. ${ }^{14,15}$ However, the risk relates to the population risks of incarcerated individuals, rather than the risk of infection within prison. The work of Dwyer et al. proposed this 10 years previously. ${ }^{17}$ Our study supports this hypothesis.

No undetected cases of active tuberculosis were identified by either survey, indicating that the risk of transmission of tuberculosis infection in the NSW prison system is low. If similar conditions existed in NSW to those found in European prisons, we could reasonably have expected to detect some active cases of tuberculosis; however, this did not eventuate.

The risk factors for Mantoux positivity have remained the same between 1996 and 2001. Certain risk factors are predictors of Mantoux positivity and should be used to prioritise screening for tuberculosis infection in Australian prisons. Birth overseas was a significant risk factor. In $2001,79 \%$ of new tuberculosis cases in Australia occurred in overseas-born persons (particularly, those from high 
Table 2. Mantoux positivity in NSW prisoners according to year of survey, demographic characteristics, and adjusted odds ratios, 1996 and 2001

\begin{tabular}{|c|c|c|c|c|c|c|}
\hline & No. tested & $\begin{array}{l}\text { No. Mantoux } \\
\text { positive (\%) }\end{array}$ & $p$-value & Adjusted OR & $95 \% \mathrm{Cl}$ & $p$-value \\
\hline Total & 1442 & $191(13)$ & & & & \\
\hline \multicolumn{7}{|l|}{ Year of survey } \\
\hline 1996 & 639 & $76(12)$ & & 1.0 & & \\
\hline 2001 & 803 & $115(14)$ & 0.2 & 1.2 & $0.9-1.7$ & 0.3 \\
\hline \multicolumn{7}{|l|}{ Sex } \\
\hline Male & 1190 & $162(14)$ & & 1.0 & & \\
\hline Female & 252 & $29(12)$ & 0.4 & 0.7 & $0.5-1.1$ & 0.2 \\
\hline \multicolumn{7}{|l|}{ Age } \\
\hline$<25$ years & 432 & $26(6)$ & & 1.0 & & \\
\hline $25-40$ years & 602 & $85(14)$ & & 2.9 & $1.8-4.6$ & $<0.001$ \\
\hline$>40$ years & 407 & $80(20)$ & $<0.001$ & 3.8 & $2.3-6.2$ & $<0.001$ \\
\hline \multicolumn{7}{|l|}{ Aboriginal } \\
\hline No & 1028 & $143(14)$ & & 1.0 & & \\
\hline Yes & 414 & $48(12)$ & 0.2 & 1.6 & $1.0-2.3$ & 0.03 \\
\hline \multicolumn{7}{|l|}{ Region of birth } \\
\hline Australia & 1139 & $105(9)$ & & 1.0 & & \\
\hline Oceania (other) & 64 & $8(13)$ & & 2.0 & $0.9-4.5$ & 0.09 \\
\hline Asia & 85 & $32(38)$ & & 8.3 & $4.9-14.1$ & $<0.001$ \\
\hline Europe & 76 & $30(39)$ & & 6.0 & $3.4-10.4$ & $<0.001$ \\
\hline Other & 35 & $11(31)$ & & 5.0 & $2.3-10.9$ & $<0.001$ \\
\hline Not reported & 43 & $5(12)$ & $<0.001$ & - & - & - \\
\hline \multicolumn{7}{|c|}{ Previous BCG vaccination } \\
\hline No & 1325 & $166(13)$ & & 1.0 & & \\
\hline Yes & 117 & $25(21)$ & 0.007 & 1.0 & $0.6-1.8$ & 0.9 \\
\hline
\end{tabular}

prevalence countries such as Vietnam, China, the Philippines, India and Indonesia). ${ }^{18}$ Among the Australian-born participants, $21 \%$ of new cases were reported as being Aboriginal, ${ }^{18}$ a group who are significantly overrepresented in NSW prisons $(1.4 \%$ of the general population but approximately $20 \%$ of the NSW prisoner population). ${ }^{19}$

This study experienced logistical problems associated with conducting Mantoux screening in prisons, with a number of prisoners unavailable for follow-up skin test readings and for chest $\mathrm{x}$-rays. This inability to follow-up prisoners was primarily due to release from gaol or internal loss due

Table 3. Mantoux test results among NSW prisoners who participated in the 1996 and 2001 Inmate Health Surveys

\begin{tabular}{l|rcr}
\hline Mantoux test 1996 & \multicolumn{3}{|c}{ Mantoux test 2001 } \\
& Negative & Positive & Total \\
\hline Negative & 79 & 18 & 97 \\
Positive & 2 & 5 & 7 \\
Total & 81 & 23 & 104 \\
\hline
\end{tabular}

to transfers within the prison system. Some prisoners were unable to attend local chest x-ray clinics or hospitals for security reasons. These issues have been highlighted in a previous report. ${ }^{3}$ Further research is required to assess the management of the Mantoux converters.

Mantoux conversion occurs when a person with a previously negative Mantoux test result shows a positive result, indicating that the person has become exposed to M. tuberculosis. By definition, it is an incident case of infection, but not an incident case of disease (a diagnosis dependent on sputum examination, x-ray and clinical signs and symptoms). Importantly, recently infected individuals are rarely infectious themselves, ie, they do not excrete organisms into the environment. We identified 10 continuously detained Mantoux converters, suggesting that infection occurred while the custodial authority had a 'duty of care' for the individual. It does not indicate at which time or place the conversion occurred.

There have been numerous reports of prison-to-community spread of tuberculosis. ${ }^{17,20}$ We were concerned about an undetected ongoing micro-epidemic in the prison 
Table 4. Demographic characteristics of Mantoux converters among NSW prisoners who participated in the 1996 and 2001 Inmate Health Surveys

\begin{tabular}{lccc}
\hline & $\begin{array}{c}\text { No. } \\
\text { participants }\end{array}$ & $\begin{array}{c}\text { No. Mantoux } \\
\text { conversion (\%) }\end{array}$ & p-value \\
\hline $\begin{array}{l}\text { Total } \\
\text { Sex }\end{array}$ & 97 & $18(19)$ & \\
$\quad$ Male & 86 & $17(20)$ & 0.4 \\
$\quad$ Female & 11 & $1(9)$ & \\
Age (in 2001) & & $7(17)$ & 0.9 \\
$<25$ years & 41 & $7(21)$ & \\
$25-40$ years & 33 & $4(17)$ & 0.9 \\
$>40$ years & 23 & $14(19)$ & \\
Aboriginal & & $4(18)$ & \\
No & 75 & $15(18)$ & \\
Yes & 22 & $0(0)$ & 0.7 \\
Region of birth & & $1(33)$ & \\
Australia & 81 & $1(33)$ & \\
Oceania (other) & 3 & $0(0)$ & \\
Asia & 3 & $10(21)$ & \\
Europe & 3 & $8(16)$ & \\
Other & 4 & & \\
Not reported & 3 & & \\
Continuous imprisonment & 48 & & \\
Yes & & & \\
No & 49 & & \\
\hline
\end{tabular}

system, as evidenced by the Mantoux conversions among the 1996-2001 cohort. However, we were unable to identify a point-source of infection due to the nature of the study, a population-based cross-sectional survey.

It is notable that there was no difference in annual risk of infection between recidivists and those continuously incarcerated. This situation indicates that the risk of exposure to $M$. tuberculosis is related to the antecedents of incarceration and not to the prison environment itself. This hypothesis may only be applicable to low prevalence environments for both tuberculosis and HIV. The contrary position has been proposed in a high tuberculosis prevalence environment, where distinct risks for community and prison are reported. ${ }^{21}$

Importantly, the higher prevalence of tuberculosis infection among prisoners was similar in the two subgroups within the cohort - those continuously incarcerated and those who had spent some of the intervening period in the community. We were unable to attribute a specific risk of tuberculosis infection to incarceration, rather the risk may be common to that subsection of the general population who are prisoners. This situation is in distinct contrast to the situation with hepatitis $\mathrm{C}$ and Australian prisons. $^{22}$ In low-tuberculosis-incidence countries like Australia, prisons are not a reservoir of infection but a temporary repository of people with higher exposure to tuberculosis.

Despite improvements in the delivery of health services to prisoners and better surveillance capacity, the imprecision of the diagnosis of tuberculosis infection and the substantial risk of false-positive results in a low prevalence population precludes against recommending routine Mantoux screening for NSW prisoners. The hallmark of tuberculosis control will remain rapid identification of active disease, with prompt isolation of tuberculosis suspects. Sputum microscopy remains the 'gold standard' for diagnosis as the assessment of public health risk is critical in mounting a response to tuberculosis in a low-prevalence country.

Justice Health and the Department of Corrective Services now have an effective referral process to the negative pressure cells at the Long Bay Hospital, based on the principles of early referral, infection control and secure and safe transportation. The link between the governance structure of prisoner health and the potential benefits to public health, have been proposed in the context of tuberculosis. ${ }^{23}$ NSW prisoners are provided with health care directly from community health funds through an independent health authority, Justice Health NSW. This position is consistent with that proposed by Baroness Stern: ${ }^{23}$ 
'Restructuring the prison medical service so that it is part of the national health system has been regarded as a prerequisite of the protection of prisoners' rights.'

While the risk of tuberculosis transmission in the NSW prison system is currently considered to be low, prisoners can be sentinels for community based tuberculosis control programs. With good control programs in the community and proper governance of prisoner health services, the public health is well served. In low-prevalence situations, prisoners can be protected, and prisons may not pose added health risk to the community. This has been the Australian experience with HIV. ${ }^{24}$ So too with tuberculosis.

\section{References}

1. MacIntyre CR, Carnie J, Randall M. Risk of transmission of tuberculosis among prisoners of an Australian prison. Epidemiol Infect 1999; 123: 445-50. doi:10.1017/S095026889900312X

2. Reichard AA, Lobato MN, Roberts CA, Bazerman LB, Hammett TM. Assessment of tuberculosis screening and management practices of large jail systems. Pub Health Rep 2003; 118: 500-7.

3. Levy MH, Quilty S, Young LC, Hunt W, Matthews R, Robertson PW. Pox in the docks: varicella outbreak in an Australian prison system. Public Health 2003; 117: 446-51. doi:10.1016/S0033-3506(03)00138-0

4. Levy MH, Gater C. The cough that packed a punch: is boxing a risk for tuberculosis transmission? Med J Aust 2000; 173: 671.

5. Bellin EY, Fletcher DD, Safyer SM. Association of tuberculin infection with increased time or admission to the New York jail system. JAMA 1993; 269: 2228-31. doi:10.1001/jama.269.17.2228

6. Conaty S, Christiansen A, Butler T, McCauley J, Goldberg H. Tuberculosis in NSW correctional centres: disease control measures following infectious cases. N SW Public Health Bull 1996; 7: 138-9.

7. Butler T. Preliminary findings of the NSW Inmate Health Survey. Sydney: NSW Corrections Health Service, 1997.

8. Butler T, Milner L. The 2001 Inmate Health Survey. Sydney: NSW Corrections Health Service, 2003.

9. Butler T, Levy M. Mantoux positivity among prison prisoners - New South Wales, 1996. Aust N Z J Public Health 1999; 23: $185-8$.

10. NSW Department of Health. Tuberculin skin testing. Policy Directive. PD2005_580. Sydney: NSW Department of Health, 2005.
11. The Offender Management System. Electronic database. Sydney: Department of Corrective Services.

12. Bleiker MA, Sutherland I, Styblo K, ten Dam HG, Misljenovic O. Guidelines for estimating the risks of tuberculosis infection from tuberculin test results in a representative sample of children. Bull Int Union Tuberc Lung Dis 1989; 64: 7-12.

13. STATA 8.2 for Windows [statistical package]. College Station, TX: StataCorp, 2005

14. Coolahan LM, Levy MH. The prevalence of tuberculosis infection in New South Wales police recruits, 1987-1990. Med J Aust 1993; 159: 369-72.

15. Alperstein G, Fett MJ, Reznik R, Thomas M, Senthil M. The prevalence of tuberculosis infection among Year 8 schoolchildren in 1992. Med J Aust 1994; 160: 197-201.

16. Alperstein G, Morgan KR, Fett MJ, Nossar V, Stewart GJ. Prevalence of tuberculosis infection among primary schoolentry children. Aust NZ J Pub Health 1996; : 123-8.

17. Dwyer B, Jackson K, Raios K, Sievers A, Wilshire E, Ross B. DNA restriction fragment analysis to define an extended cluster of tuberculosis in homeless men and their associates. J Infect Dis 1993; 167: 490-4.

18. Miller M, Lin M, Spencer J, Antic R, Bastion I, Christensen A et al. Tuberculosis notifications in Australia, 2001. Commun Dis Intell 2002; 26: 525-36.

19. Australian Bureau of Statistics. Prisoners of Australia 2006. Cat. no. 4517.0. Canberra: Australian Bureau of Statistics, 2006.

20. Stead WW. Undetected tuberculosis in prison. Source of infection for community at large. JAMA 1978; 240: 2544-7. doi:10.1001/jama.240.23.2544

21. Kimerling ME, Slavuckij A, Chavers S et al. The risk of MDRTB and polyresistant tuberculosis among the civilian population of Tomsk city, Siberia 1999. Int J Tuberc Lung Dis 2003; 7: 866-72.

22. van Beek I, Dwyer R, Dore GJ, Luo K, Kaldor JM. Infection with HIV and hepatitis $\mathrm{C}$ virus among injecting drug users in a prevention setting: retrospective cohort study. BMJ 1998; 317: 433-7.

23. Stern V. Prison reform and public health. The case of tuberculosis in the former Soviet Union. Eur J Public Health 2000; 10: 4. doi:10.1093/eurpub/10.1.4

24. McDonald AM, Ryan JW, Brown PR, Manners CJ, Falconer AD, Kinnear RC et al. HIV prevalence at reception into Australian prisons, 1991-1997. Med J Aust 1999; 171: $18-21$. 


\section{Recent substance use and high levels of psychological distress among secondary school students in New South Wales}

\author{
Tom F. Norris ${ }^{\mathrm{A}}$ and Margo L. Eyeson-Annan ${ }^{\mathrm{A}, \mathrm{B}}$ \\ ${ }^{\mathrm{A} C e n t r e ~ f o r ~ E p i d e m i o l o g y ~ a n d ~ R e s e a r c h, ~ P o p u l a t i o n ~ H e a l t h ~}$ \\ Division NSW Department of Health \\ ${ }^{\mathrm{B} C o r r e s p o n d i n g ~ a u t h o r . E m a i l: ~ m e y e s @ d o h . h e a l t h . n s w . g o v . a u ~}$
}

\begin{abstract}
In 2002, the NSW Department of Health, in conjunction with The Cancer Council NSW, carried out the NSW School Students Health Behaviours Survey. The methodology and summary descriptive results have been previously described [NSW Department of Health. The health behaviours of secondary school students in New South Wales 2002. N S W Public Health Bull 2004; 15(S-2): 1-86]. In the survey, $18 \%$ of NSW secondary school students reported high levels of psychological distress, $30 \%$ reported recently using alcohol, 13\% reported recently using tobacco, and $9 \%$ reported recently using cannabis. With regard to the other illicit drugs, $2.0 \%$ reported recently using amphetamines, $1.0 \%$ cocaine, $1.4 \%$ hallucinogens (LSD, heroin) and $1.9 \%$ ecstasy. The survey did not, however, examine associations between substance use and high levels of psychological distress. These associations are described in this article.
\end{abstract}

In 2002, the NSW Department of Health, in conjunction with The Cancer Council NSW, carried out the NSW School Students Health Behaviours Survey. ${ }^{1}$ Previous interstate and overseas studies have identified an association between substance use and psychological distress in adolescents. ${ }^{2-5}$ A cross-sectional survey of Victorian secondary school students found that students reporting high levels of anxiety and depression were almost twice as likely to report using tobacco after controlling for potential confounders including year level, sex, alcohol use and parental tobacco use. ${ }^{6}$ A United Kingdom study of adolescents aged 13-15 years found that both regular tobacco users and regular alcohol users were four times more likely to have a psychiatric disorder. They also found that regular tobacco users who also used cannabis or cannabis and alcohol were seven and 14 times more likely to have a psychiatric disorder, respectively. ${ }^{7}$ In a recent prospective cohort study, cannabis use was also found to moderately increase the risk of psychotic symptoms in young people but with a much stronger effect in those with evidence of predisposition for psychosis. ${ }^{8}$

However, interpretation and comparison of these various studies are made difficult because of the varying definitions and methods used to assess substance use and mental health problems. The basis for this association, including its causation and strength, is unclear, as is the effect of the possible interaction between the various substances and of confounders such as age and sex.

A recent review of cannabis use concluded that although an association between cannabis use and depression and anxiety existed in adolescents it had not been established whether the relationship was causal. ${ }^{9}$ Several alternative hypotheses have been cited in the literature to explain the associations between substance use and mental health disorders other than a causative one. These include:

(1) the self-medication theory, which states that drug abuse is driven by attempts to alleviate psychological distress;

(2) a reciprocal relationship between the two where unhappiness brings about substance use, which in turn results in unhappiness, which may then result in symptoms greater than the sum of their individual effects;

(3) substance use reflects a 'willingness to contravene the law'; and

(4) substance misuse is the result of other confounding features in their lives, which cause psychological distress and substance use. ${ }^{9}$

The school setting provides an opportunity to further examine the association between substance use and high psychological distress across a broad range of adolescents. No recent studies on this association in Australia have been published. This article explores whether there are associations between substance use, either alone or in combination, and high psychological distress in NSW secondary school students aged $12-17$ years. It considers the strength of any such associations, and discusses the impli- 
cations of any associations for ongoing monitoring, and policy and program development.

\section{Methods}

Measures

High psychological distress was based on the student reporting feelings of depression, anxiety, stress, or being in trouble about their behaviour in the last six months, using three questions from the Western Australian Child Health Survey (WACHS), ${ }^{10}$ which were based on items adapted from the Achenbach Child Behaviour Checklists and the Mental Health Inventory. ${ }^{1-13}$ Those who had experienced a problem were asked 'how bad' it was for them at the time. A student who responded 'almost more than I can take' to any of the three problems was considered to have experienced high psychological distress.

Recent substance use included alcohol in the last week, tobacco smoking in the last week, cannabis in the last four weeks, and 'other illicit drugs' (including amphetamines, cocaine, LSD, heroin, ecstasy only) in the last four weeks.

Socioeconomic status was determined by allocating students to quintiles based on postcode, ranked from least to most disadvantaged, using the Index of Relative SocioEconomic Disadvantage. ${ }^{14}$

Age was dichotomised into two groups (12-15 years and $16-17$ years). These age groups correspond approximately to junior and senior secondary school years.

\section{Source of data}

The source of data was the NSW School Students Health Behaviours Survey 2002 (HOIST). ${ }^{15}$ The survey instrument was a self-administered questionnaire, which had a core questionnaire and two supplementary questionnaires. The recent substance use questions were included in the core questionnaire and the psychological distress questions were included in one of the supplementary questionnaires. This gave a sample of 3506 students who had completed both the recent substance use and psychological distress questions.

\section{Data analysis}

The data were analysed using SAS version 8.02.16 The SURVEYMEANS procedure was used to calculate the estimated prevalence and $95 \%$ confidence intervals for all students and for students by age and sex. Cox's proportional hazard regression model, with time fixed at 1, was used to calculate estimated prevalence rate ratios and their 95\% confidence intervals separately for each subgroup using SUDAAN where there were sufficient clusters within the strata and to adjust for socioeconomic status. ${ }^{17}$

The analysis was weighted to adjust for differences between the survey sample and the target population of secondary school students caused by stratification and clustering in the survey design and non-response. The data were analysed, stratifying by school sector (government, Catholic and independent) and level (junior secondary, up to year 10, and senior secondary, years 11 and 12), and clustering by the individual school from which the student came.

\section{Results}

\section{Recent substance use}

Almost 36\% (35.6\%) of all students reported using substances recently. Twenty-three percent reported using only one substance $(17.4 \%$ alcohol, $3.4 \%$ tobacco, $1.2 \%$ cannabis and $0.7 \%$ other illicit drugs) (Table 1 ).

A significantly higher proportion of students aged 16-17 years used any substances recently (49.1\%) compared with 13-15 year olds (30.4\%). This age difference was consistent for any tobacco use (24.7\% versus 9.6\%), drinking any alcohol (38.3\% versus $25.3 \%)$, and using two or more substances $(17.9 \%$ versus $7.1 \%)$.

There was no significant difference seen in the recent use of any substances according to sex except for a higher proportion of males $(11.2 \%)$ using any cannabis compared with females $(7.4 \%)$.

\section{High psychological distress}

High psychological distress was reported by $17.5 \%$ of secondary school students in the 2002 survey. A significantly higher proportion of females $(21.5 \%$; $95 \%$ CI: 19.0-24.0\%) had high psychological distress compared with males (13.5\%; 95\% CI: 11.3-15.6\%). This difference was present in both substance users and non-users. There was no difference in high psychological distress between the $12-15$ years and $16-17$ years age groups.

\section{Recent substance use and high psychological distress}

Of all students, 8.4\% (95\% CI: 7.1-9.7\%) had both recently used substances and experienced high psychological distress, $27.1 \%$ (95\% CI: 24.8-29.5\%) of all students had recently used substances and not suffered from high psychological distress, while $8.9 \%$ (95\% CI: 7.1-9.7\%) of all students had high psychological distress but had not recently used substances. Just over half of students (55.4\%; 95\% CI: 52.7-58.1\%) had neither recently used substances nor suffered from high psychological distress.

Almost one quarter (23.7\%) of students who recently used substances had experienced psychological distress, compared with $13.8 \%$ among students who had not recently used substances. Of students with high psychological distress almost half (48.2\%; 95\% CI: 42.2-54.2\%) had used substances recently compared with $33.0 \%$ (95\% CI: $30.0-36.0 \%$ ) of students without high psychological distress.

As the proportion of students with high psychological dis- 
Table 1. Recent substance use for all students and by age and sex, NSW, 2002

\begin{tabular}{|c|c|c|c|c|c|}
\hline Substance use pattern & $\begin{array}{l}\text { Males } \\
\%(95 \% \mathrm{Cl})\end{array}$ & $\begin{array}{l}\text { Females } \\
\%(95 \% \mathrm{Cl})\end{array}$ & $\begin{array}{l}12-15 \text { years } \\
\%(95 \% \mathrm{Cl})\end{array}$ & $\begin{array}{l}16-17 \text { years } \\
\%(95 \% \mathrm{Cl})\end{array}$ & $\begin{array}{l}\text { All students } \\
\%(95 \% \mathrm{Cl})\end{array}$ \\
\hline Any substance & $34.9(31.0-38.8)$ & $36.2(33.0-44.0)$ & $30.4(27.5-33.2)$ & $49.1(43.6-54.5)$ & $35.6(32.7-38.4)$ \\
\hline Alcohol only & $18.5(16.3-20.8)$ & $16.3(14.0-18.5)$ & $17.0(15.0-18.1)$ & 19.6(16.1-23.2) & $17.4(15.8-19.0)$ \\
\hline Any alcohol & $29.8(27.1-32.5)$ & $28.0(25.2-30.8)$ & $25.3(22.3-27.8)$ & $38.3(32.3-43.8)$ & $28.9(26.9-30.8)$ \\
\hline Tobacco only & $2.2(1.3-3.1)$ & $4.7(3.0-6.3)$ & $2.4(1.6-3.1)$ & $6.3(3.5-9.0)$ & $3.4(2.5-4.4)$ \\
\hline Any tobacco & $12.2(10.1-14.3)$ & $15.4(12.9-17.8)$ & $9.6(7.9-11.3)$ & 24.7(19.5-29.8) & $13.8(12.2-15.4)$ \\
\hline Cannabis only & $1.6(0.8-2.4)$ & $0.9(0.4-1.4)$ & $1.0(0.6-1.5)$ & $1.8(0.2-3.4)$ & $1.2(0.8-1.7)$ \\
\hline Any cannabis & $11.2(9.2-13.2$ & $7.4(5.8-9.0)$ & $7.8(6.6-9.2)$ & $13.2(8.5-17.7)$ & $9.3(8.0-10.6$ \\
\hline Illicit drugs only & $0.7(0.3-1.1)$ & $0.7(0.2-1.2)$ & $0.9(0.5-1.3)$ & $0.3(0-0.7)$ & $0.7(0.4-1.0)$ \\
\hline Any other illicits & $4.6(3.4-5.9)$ & $3.1(1.9-4.2)$ & $3.3(2.5-4.1)$ & $5.3(3.1-7.4)$ & $3.9(3.0-4.7)$ \\
\hline Two substances & $4.7(3.6-5.8)$ & $3.4(2.2-4.5)$ & $3.9(2.9-4.8)$ & $4.6(2.4-6.8)$ & $4.1(3.1-5.0)$ \\
\hline Three substances & $5.1(3.6-6.6)$ & $2.7(1.7-3.7)$ & $2.7(2.0-3.5)$ & $6.9(4.9-9.0)$ & $3.9(3.1-4.7)$ \\
\hline $\begin{array}{l}\text { All drugs (alcohol, tobacco, } \\
\text { illicit drugs and cannabis) }\end{array}$ & $1.0(0.5-1.5)$ & $1.2(0.4-2.0)$ & $0.8(0.5-1.2)$ & $1.9(0.1-3.6)$ & $1.1(0.6-1.6)$ \\
\hline More than one substance & $9.9(8.2-11.6)$ & $10.3(8.0-12.5)$ & $7.1(5.7-8.4)$ & $17.9(13.5-22.3)$ & $10.1(8.4-11.8)$ \\
\hline No substances & $63.1(60.2-65.9)$ & $64.4(61.4-67.4)$ & $68.8(66.0-72.0)$ & $50.7(45.3-56.0)$ & $63.7(61.7-65.8)$ \\
\hline \multicolumn{6}{|c|}{$\begin{array}{l}\text { Note: Recent substance use included alcohol in the last week, tobacco smoking in the last week, cannabis in the last four weeks, and 'other illicit } \\
\text { drugs' (amphetamines, cocaine, LSD, heroin, ecstasy) in the last four weeks. }\end{array}$} \\
\hline \multicolumn{6}{|c|}{$\begin{array}{l}\text { Data source: } 2002 \text { New South Wales School Students Health Behaviours Survey (HOIST, Health Outcomes Information and Statistics Toolkit). } \\
\text { Analysis: NSW Health Survey Program, Centre for Epidemiology and Research, NSW Department of Health. } \\
\text { Cl, confidence interval. }\end{array}$} \\
\hline
\end{tabular}

tress who had only used one drug recently (alcohol only, $20 \%$; tobacco only, $21.7 \%$; cannabis only, $22.7 \%$; other illicit drugs only, $32 \%$ ) was not significantly different from students with any recent use of that substance whether alone or in combination with other substances (any alcohol, 24.1\%; any tobacco, $28.2 \%$; any cannabis,
$27.5 \%$; any other illicit drugs, $33.6 \%$ ), comparisons of high psychological stress in users and non-users was completed using 'any' recent use of a substance (Table 2).

Overall, the prevalence of high psychological distress was higher in recent substance users $(23.7 \%)$ compared with

Table 2. High psychological distress by recent substance use for all students and by age and sex, NSW, 2002

\begin{tabular}{lccccc}
\hline Substance & $\begin{array}{c}\text { Males } \\
\%(95 \% \mathrm{Cl})\end{array}$ & $\begin{array}{c}\text { Females } \\
\%(95 \% \mathrm{Cl})\end{array}$ & $\begin{array}{c}12-15 \text { years } \\
\%(95 \% \mathrm{Cl})\end{array}$ & $\begin{array}{c}16-17 \text { years } \\
\%(95 \% \mathrm{Cl})\end{array}$ & $\begin{array}{c}\text { All students } \\
\%(95 \% \mathrm{Cl})\end{array}$ \\
\hline Any substance & $17.3(13.2-21.4)$ & $30.3(26.4-34.2)$ & $22.7(19.2-26.1)$ & $25.3(19.2-31.2)$ & $23.7(20.6-26.7)$ \\
Alcohol only & $15.3(10.3-20.3)$ & $25.5(19.0-31.9)$ & $19.7(15.3-24.1)$ & $20.8(14.5-27.0)$ & $20.0(16.0-24.1)$ \\
Any alcohol & $17.7(13.7-21.6)$ & $31.0(26.8-35.2)$ & $23.5(19.7-27.3)$ & $25.3(20.8-29.8)$ & $24.1(21.2-27.1)$ \\
Tobacco only & $19.9(1.9-37.9$ & $22.5(8.2-36.8)$ & $12.9(3.3-22.4)$ & $30.3(7.0-53.6)$ & $21.7(10.4-32.9)$ \\
Any tobacco & $17.7(13.7-21.6)$ & $31.0(26.8-35.2)$ & $27.4(21.6-33.2)$ & $29.0(20.2-37.8)$ & $28.2(23.1-33.3)$ \\
Cannabis only & $16.0(0.0-41.3$ & $35.0(6.0-63.9)$ & $18.4(0.8-36.0)$ & $29.1(0-84.4)$ & $22.7(3.1-42.4)$ \\
Any cannabis & $17.8(10.2-25.5)$ & $42.1(32.9-51.3)$ & $28.2(20.6-35.8)$ & $26.4(14.7-38.1)$ & $27.5(20.9-34.1)$ \\
Other illicits only & $17.2(0.0-42.2)$ & $47.2(10.4-83.9)$ & $27.4(4.2-50.6)$ & $32.4(0-74.0)$ & $32.0(9.9-54.1)$ \\
Any other illicit & $29.2(16.7-41.8)$ & $40.3(24.9-55.8)$ & $34.1(22.8-45.3)$ & $32.9(13.4-52.5)$ & $33.6(23.4-43.9)$ \\
Two substances & $14.2(6.8-21.6)$ & $37.1(22.7-51.4)$ & $26.0(16.9-35.0)$ & $18.7(4.3-33.2)$ & $23.7(16.1-31.3)$ \\
Three substances & $24.2(11.0-37.4)$ & $33.2(18.9-47.4)$ & $30.6(20.0-41.3)$ & $24.0(8.2-40.0)$ & $27.3(17.5-37.5)$ \\
All four substances & $32.3(12.7-52.0)$ & $65.3(46.8-83.8)$ & $50.2(29.0-71.3)$ & $50.7(17.0-84.4)$ & $50.4(32.0-68.8)$ \\
More than one substance & $23.8(15.8-31.7)$ & $38.1(31.1-45.1)$ & $33.3(25.3-41.4)$ & $28.7(21.5-35.9)$ & $31.0(26.0-36.2)$ \\
No substances & $11.2(9.0-13.4)$ & $16.4(13.4-19.5)$ & $13.2(10.9-15.5)$ & $13.8(11.3-20.7)$ & $13.8(12.0-15.7)$ \\
\hline
\end{tabular}

Note: Recent substance use included alcohol in the last week, tobacco smoking in the last week, cannabis in the last four weeks, and 'other illicit drugs' (amphetamines, cocaine, LSD, heroin, ecstasy) in the last four weeks.

Data source: 2002 New South Wales School Students Health Behaviours Survey (HOIST, Health Outcomes Information and Statistics Toolkit). Analysis: NSW Health Survey Program, Centre for Epidemiology and Research, NSW Department of Health.

$\mathrm{Cl}$, confidence interval. 
Table 3. Prevalence rate ratios for high psychological distress by 'any' recent substance use for all students and by age and sex, NSW, 2002

\begin{tabular}{|c|c|c|c|c|c|}
\hline Substance & $\begin{array}{l}\text { Males PRR } \\
(95 \% \mathrm{Cl})\end{array}$ & $\begin{array}{l}\text { Females PRR } \\
\quad(95 \% \mathrm{Cl})\end{array}$ & $\begin{array}{l}\text { 12-15 years PRR } \\
(95 \% \mathrm{Cl})\end{array}$ & $\begin{array}{l}16-17 \text { years PRR } \\
95 \% \mathrm{Cl})\end{array}$ & $\begin{array}{l}\text { All students } \\
\text { PRR }(95 \% \mathrm{Cl})\end{array}$ \\
\hline Any alcohol & $1.5(1.2-2.0)$ & $1.7(1.4-2.2)$ & $1.7(1.4-2.1)$ & $1.4(1.1-1.7)$ & $1.6(1.4-1.9)$ \\
\hline Any other illicits & $2.3(1.5-3.6)$ & $1.9(1.3-2.8)$ & $2.2(1.6-3.0)$ & $1.6(1.01-2.8)$ & $2.0(1.5-2.7)$ \\
\hline Any cannabis & $1.4(0.9-2.2)$ & $2.1(1.7-2.7)$ & $1.9(1.4-2.5)$ & $1.3(0.9-2.1)$ & $1.7(1.3-2.2)$ \\
\hline Any tobacco & $1.5(1.2-2.0)$ & $1.7(1.4-2.2)$ & $1.8(1.5-2.3)$ & $1.6(1.2-2.3)$ & $1.8(1.5-2.2)$ \\
\hline Any substance & $1.5(1.2-2.0)$ & $1.8(1.4-2.3)$ & $1.7(1.4-2.1)$ & $1.5(1.01-2.3)$ & $1.7(1.4-2.1)$ \\
\hline Any substance adjusted for SES & $1.6(1.2-2.1)$ & $1.8(1.4-2.3)$ & $1.7(1.4-2.1)$ & $1.6(1.1-2.3)$ & $1.7(1.4-2.1)$ \\
\hline More than one substance & $1.7(1.2-2.4)$ & $2.1(1.7-2.5)$ & $2.1(1.6-2.7)$ & $1.5(1.3-1.9)$ & $1.9(1.6-2.2)$ \\
\hline \multicolumn{6}{|c|}{$\begin{array}{l}\text { Note: Recent substance use included alcohol in the last week, tobacco smoking in the last week, cannabis in the last four weeks, and 'other illicit } \\
\text { drugs' (amphetamines, cocaine, LSD, heroin, ecstasy) in the last four weeks. }\end{array}$} \\
\hline \multicolumn{6}{|c|}{$\begin{array}{l}\text { Data source: } 2002 \text { New South Wales School Students Health Behaviours Survey (HOIST, Health Outcomes Information and Statistics Toolkit). } \\
\text { Analysis: NSW Health Survey Program, Centre for Epidemiology and Research, NSW Department of Health. }\end{array}$} \\
\hline ence rate ratio. Cl, confid & 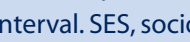 & nomic status. & & & \\
\hline
\end{tabular}

non-users (14.0\%) (PRR 1.7; 95\% CI: 1.4-2.1). This was consistent for alcohol (PRR 1.6; 95\% CI: 1.4-1.9), tobacco (PRR 1.8; 95\% CI: 1.5-2.2), cannabis (PRR 1.7; 95\% CI: $1.3-2.2$ ) other illicit drugs (PRR 2.0; 95\% CI: 1.5-2.7) and two or more drugs (PRR 1.9; 95\% CI: 1.6-2.2) (Table 3).

The association between high psychological distress and recent substance users of any of the four categories of substances was consistent for all students, younger (junior secondary), older (senior secondary), male and female students. The association between high psychological distress and recent use in all students, younger (junior secondary), older (senior secondary), male and female students was also consistent for use of any alcohol, use of any tobacco, use of any other illicit drugs and use of more than one substance. However, there was no association between high psychological distress and cannabis use in males or in students over 16 years. We were unable to examine this association by age and sex due to inadequate numbers of clusters within strata. The association with 'any' recent substance use was not affected when adjusted for socioeconomic status (Table 3).

\section{Discussion}

Recent substance use is associated with high psychological distress in NSW secondary school students for all substances. Just over $8 \%$ of NSW secondary school students were found to have both engaged in recent substance use and experienced high levels of psychological distress. This subgroup of students appears to constitute a potentially vulnerable minority of students in NSW schools that is at high risk of acute and long-term psychological and health problems.

Students who reported recent substance use were more likely to have high psychological distress than those who did not for all students, both sexes, and most age groups.
The results are consistent with a large number of studies..$^{2-9}$ The strength of the association with high psychological distress found in this study in a school setting was, however, less than that reported for recent substance use in a community sample of teenagers aged 13-15 years with a psychiatric diagnosis based on structured interview. $^{7}$ In contrast, the strengths of the associations between high psychological distress and recent substance use are similar to those found for adults and adolescents in Australia and the United States (odds ratio of about $1.5-2.0){ }^{18-24}$

Although the substances studied have varying pharmacological effects, the strength of association found between high psychological distress and recent substance use did not vary significantly between substances. This suggests a non-pharmacological association and that the effect of recent substance use in this association represents a general type of behaviour rather than one related to the specific properties of a particular drug. Although no dose response curve was able to be determined, taking more than one drug did not make high psychological distress more likely.

As the NSW School Students Health Behaviours Survey is repeated every three years, it provides the opportunity to monitor the effectiveness of school programs by using as indicators the prevalence of recent substance use, high psychological distress, and both high psychological distress and recent substance use among students.

\section{Conclusion}

Recent substance use is associated with high psychological distress in NSW secondary school students for all substances. A significant minority of students appear to be at high risk. The lack of variation in the association between substances suggests a non-pharmacological association. 


\section{Acknowledgements}

The authors wish to thank Baohui Yang (statistical support), Michael Giffin (editing), and Lee Taylor (managerial support and data management) from the Centre for Epidemiology and Research, NSW Department of Health. Also Margaret Thomas from the Centre for Chronic Disease Prevention and Health Advancement, NSW Department of Health; Beverley Raphael, and Gavin Stewart from the Centre for Mental Health, NSW Department of Health; and Devon Indig from the Centre for Drug and Alcohol Programs, NSW Department of Health, for providing helpful comments.

\section{References}

1. NSW Department of Health The health behaviours of secondary school students in New South Wales 2002. N S W Public Health Bull 2004; 15: 1-86. S-2

2. Maney DW, Higham-Gardill DA, Mahoney BS. The alcoholrelated psychosocial and behavioural risks of a nationally representative sample of adolescents. J Sch Health 2002; 72(4): 157-63.

3. Henderson S, Lewis IC, Howell RH, Rayner KJ. Mental health and the use of alcohol, tobacco, analgesics and vitamins in a secondary school population. Acta Psychiatr Scand 1981; 63(2): 186-9.

4. Burke JD Jr, Burke KC, Rae DS. Increased rates of drug abuse and dependence after onset of mood or anxiety disorders in adolescence. Hosp Community Psychiatry 1994; 45(5): 451-5.

5. Simantov E, Schoen C, Klein JD. Health-compromising behaviours: Why do adolescents smoke or drink? Identifying underlying risk and protective factors. Arch Pediatr Adolesc Med 2000; 154(10): 1025-33.

6. Patton GC, Hibbert M, Rosier MJ, Carlin JB, Caust J, Bowes G. Is smoking associated with depression and anxiety in teenagers? Aust J Public Health 1995; 19(4): 393-9.

7. Boys A, Farrell M, Taylor C, Marsden J, Goodman R, Brugha T, et al. Psychiatric morbidity and substance use in young people aged 13-15 years: Results from the Child and Adolescent Survey of Mental Health. Br J Psychiatry 2003; 182: 509-17. doi:10.1192/bjp.182.6.509

8. Henquet C, Krabbendam L, Spauwen J, Kaplan C, Lieb R, Wittchen $\mathrm{H}$, et al. Prospective cohort study of cannabis use, predisposition for psychosis, and psychotic symptoms in young people. $B M J 2005$; 330: 11.

9. Collins C, Connolly J, Crowley D, Morgan M. An overview of scientific and other information on cannabis. Dublin: National Advisory Committee on Drugs, 2004. Available from www.nacd.ie/publications/consequences-cannabis-report.html.

10. Zubrick SR, Silburn SR, Garton A, Burton P, Dalby R, Carlton J, et al. Western Australian child health survey: developing health and wellbeing in the nineties. ABS Catalogue no: 4303.5. Perth: Australian Bureau of Statistics and the Institute for Child Health Research, 1995.
11. Achenbach TM. Manual for the child behavior checklist/4-18 and 1991 profile. Burlington, VT: University of Vermont, 1991.

12. Achenbach TM. Manual for the child behavior checklist/2-3 and 1992 profile. Burlington, VT: University of Vermont, 1992.

13. Achenbach TM. Manual for the teachers' report form and 1991 profile. Burlington, VT: University of Vermont, 1991.

14. Australian Bureau of Statistics. Census of population and housing: socio-economic indexes for areas, Australia 2001.Catalogue no.2039/0. Canberra: ABS, 2003.

15. NSW Health Survey. New South Wales School Students Health Behaviours Survey 2002 (Hoist). Sydney: Centre for Epidemiology and Research, NSW Department of Health, 2002.

16. SAS Institute. The SAS system for Windows version 8.02.Cary, NC: SAS Institute, 2003.

17. SUDAAN release 8.0.1 Software for the statistical analysis of correlated data. Research Triangle Park, NC: Research Triangle Institute, January 2002.

18. Australian Institute of Health and Welfare. 2004 national drug strategy household survey: first results. Drug Statistics Series no. 13. AIHW Catalogue no. PHE 57. Canberra: AIHW, 2005.

19. Substance Abuse and Mental Health Services Administration. Patterns of alcohol use among adolescents and associations with emotional and behavioural problems: working paper. Rockville, MD: Office of Applied Studies, United States Department of Health and Human Services, 2000.

20. Substance Abuse and Mental Health Services Administration. Results from the 2001 national household survey on drug abuse: Volume I. Summary of national findings. Rockville, MD: Office of Applied Studies, United States Department of Health and Human Services, 2002.

21. Substance Abuse and Mental Health Services Administration. Overview of findings from the 2003 national survey on drug use and health. Rockville, MD: Office of Applied Studies, United States Department of Health and Human Services, 2004.

22. Clark D, Burkstein O. Psychopathology in adolescent alcohol abuse and dependence. Alcohol Res Health 1998; 22(2): $117-121$.

23. Deas D, Thomas S. Comorbid psychiatric factors contributing to adolescent alcohol and other drug use. Rockville, MD: National Institute on Alcohol Abuse and Alcoholism, 2002. Available from www.niaaa.nih.gov/publications/arh26-2/116121.htm.

24. Spooner C. Causes and correlates of adolescent drug abuse and implications for treatment. Drug Alcohol Rev 1999; 18(4): 453-475. 


\section{A discussion of the potential benefits to injury surveillance through inclusion of date of injury in hospitalisation data in New South Wales and}

Australia

\author{
Andrew D. Hayen ${ }^{\mathrm{A}, \mathrm{C}}$, Soufiane Boufous ${ }^{\mathrm{A}}$ and \\ James E. Harrison ${ }^{\mathrm{B}}$ \\ ${ }^{\mathrm{A}} \mathrm{NSW}$ Injury Risk Management Research Centre, \\ University of New South Wales \\ ${ }^{\mathrm{B}}$ Research Centre for Injury Studies, Flinders University \\ ${ }^{\mathrm{C} C o r r e s p o n d i n g ~ a u t h o r . E m a i l: ~ a h a y e n @ h e a l t h . u s y d . e d u . a u ~}$
}

\begin{abstract}
Most hospitalised injury cases have sudden onset at a specific time and date, due to a well-defined external cause (eg, a road crash). Date of injury is not presently recorded in routine hospital separations data in NSW or Australia, though it is in New Zealand. Benefits of adding date of injury to the Inpatient Statistics Collection would include: more accurate estimation of the population incidence of serious injury; better assessment of the health system utilisation and costs attributable to injurious events; and better linkage of hospital data with other data relevant to injury measurement and control (eg, road crash data).
\end{abstract}

Injury has been identified as a health priority area in Australia, and is the subject of three national plans endorsed in July 2005 by Australian health ministers. ${ }^{1-3}$ Injuries leading to hospitalisation include the most serious non-fatal injuries, and incur substantial costs both to the health system and society. In 2001-02, injuries accounted for about $7 \%$ of all hospitalisations in Australia. ${ }^{4}$ Highquality information about the incidence of injury leading to hospitalisation, and trends in incidence, is needed, for example, to assess the burden of injury, determine priorities for injury prevention, guide and evaluate injury prevention and assist service planning.

However, in Australia, accurate estimates of the incidence of injuries leading to hospitalisation are not readily available from routinely collected data because of multiple counting of the same injuries in estimates of the incidence of injury.
In Australia, reports on injury indicators have indicated the potential value of including information on the date of injury in routinely collected hospitalisation data., ${ }^{5,6}$ In this paper we discuss the potential benefits of adding such a variable to hospitalisation data to improve surveillance of serious injury in Australia.

\section{Identification of incident cases of injuries leading to hospitalisation}

The Inpatient Statistics Collection (ISC) covers all inpatient separations from public and private hospitals in NSW. In NSW, all hospitals are required to submit details to the NSW Department of Health about every inpatient episode of care which ends with the discharge, transfer or death of the patient, or by the patient becoming a different type of patient, requiring transfer within the same hospital. All states in Australia maintain similar collections, which suffer from the problems we describe below.

When estimating incidence of injury in a population, each new case of injury should be counted only once. However, the number of injury-related 'separations' from hospital is not equivalent to the number of incident injury cases that result in hospitalisation, because some cases of injury result in more than one episode of in-hospital care, each of which ends with a 'separation' event. Hence, patients who have been readmitted or transferred from another hospital for treatment of the same injury are recorded more than once. This is particularly an issue for patients with serious injuries who are likely to have a series of readmissions for ongoing treatment or rehabilitation, for example, patients with extensive burns who require a number of skin grafts. $^{7,8}$ In New Zealand, which to our knowledge is the only jurisdiction that captures date of injury information in hospitalisation data, it has been estimated that about $9 \%$ of all inpatient episodes that were assigned an external cause code were readmissions, ${ }^{7}$ but accurate estimates are not available for Australia. Furthermore, the rate of readmission in New Zealand is not uniform across mechanisms of injury. ${ }^{7}$ In addition, patterns of coding of the ways in which episodes in hospital end (for example, as a discharge, transfer or type-change separation) may not be constant over time in Australian hospitalisation data, or between geographical areas. ${ }^{6}$ This further complicates 
assessment of trends and differences in population incidence of cases.

The ISC does not currently contain a unique patient identifier. However, probabilistic record linkage (in this case an 'internal' linkage of the ISC to itself) can be used to identify the same patient across different episodes of care. However, reliance on the use of a unique patient identifier (or an approximate identifier obtained through record linkage) to identify repeat admissions has some drawbacks. ${ }^{8}$ For example, a presumed repeat admission with the same diagnosis and external cause codes as the first admission may in fact be an admission for a new case of injury, such as a hip fracture on the other side of the injured person's body resulting from a fall, or a second episode of intentional self-poisoning. Probabilistic data linkage is limited as it relies heavily on ICD 10 -AM codes in the principal diagnosis field to distinguish between 'multiple admissions' for the same injury event and 'new admission(s)' of the same person for a different injury event.

In the absence of a unique personal identifier and date of injury, some studies ${ }^{9,10}$ have assumed that each discharge refers to a single episode of injury, thereby resulting in an overestimation of incidence rates. Others have used one or other of two variables, 'mode of separation' and 'mode of admission', which are available in Australian hospitalisation data, to identify and omit groups of records likely to be for second or subsequent inpatient episodes concerning the same injury. ${ }^{11}$ Excluding such records assumes that the subsequent separation will be recorded and also meet the study definition of injury (eg, requiring a principal diagnosis of injury). Also, these methods cannot account for readmissions following discharge home.

If used with a unique patient identifier or record linkage, a 'date of injury' field would simplify the identification of incident cases of injury-related hospitalisations. ${ }^{12}$ Even when a unique patient identifier is not available, use of probabilistic record linkage and date of injury will enable the period between the date of injury occurrence and admission to be determined. This would provide a useful indication of whether a particular hospital admission is likely to have been the first episode in hospital due to that injury incident.

\section{Identification of incident injury events occurring in hospitals}

A 'date of injury' item would also allow a distinction to be made between injuries that occur in the community and lead to initial admission and injuries that occur during the course of an episode in hospital (for example, a fall from a hospital bed). These cases are of special importance to health care services. Accurate data on these cases are vital to inform strategies designed to prevent injury in health care institutions, particularly hospitals.

Currently, the only indication of these cases is provided by the ICD-10-AM place of occurrence codes, ${ }^{13}$ which are not specific enough to provide an accurate picture of injuries that occur after admission to hospital. Place of occurrence codes are not able to distinguish between injury sustained in a hospital or in an outpatient clinic, nor between injury sustained in hospital by an admitted patient or a visitor. Although a 'Diagnosis onset type' variable (item 000773), designed to identify postadmission conditions, is included in the National Health Data Dictionary, ${ }^{14}$ it is not recorded in the ISC in NSW.

\section{Better record linkage of hospital data to other injury-related datasets}

A date of injury item would also be beneficial to any record linkage of hospital separations data to other sources that contain information on injury, such as road crash data collected by police and workers' compensation data. Such linkages of datasets are important for providing a comprehensive picture of the circumstances and causes of injury, and are useful for providing a better understanding of the outcomes of various injuries. For linkage of road crash data with hospital discharge data, for example, date of injury in the hospital discharge data would assist assessment of whether matched records are, in fact, true matches.

\section{Latency between injury and first admission}

In Australia, it is likely that admission to hospital for an injury takes places soon after the occurrence of the injury. However, this is not always the case, and those cases in which first admission is delayed may warrant special attention. This is because late admission might mark instances of injuries not usually requiring admission that have resulted in complications, or injuries occurring in circumstances (geographical or social) leading to late presentation to hospital. Inclusion of a 'date of injury' variable would allow direct calculation of the latency between injury and first admission.

\section{Conclusion}

Prevention needs to be guided by a clear understanding of the burden of, and causal factors associated with, injury. Information about the date of injury is critical for linking these to relevant exposures, most of which are acute in nature. The availability of a 'date of injury' item in the New Zealand hospital discharge data has allowed accurate identification of first admissions for injuries, injuries occurring in health care institutions and improved injury surveillance. ${ }^{7,12}$ The introduction of such a variable to NSW and Australian hospitalisation data would result in similar outcomes and enhance the value of the data used to support injury prevention and control in NSW and Australia. 


\section{References}

1. National Public Health Partnership (NPHP). The national injury prevention and safety promotion plan: 2004-2014. Canberra: NPHP, 2004.

2. National Public Health Partnership (NPHP). The national Aboriginal and Torres Strait Islander safety promotion strategy. Canberra: NPHP, 2004.

3. National Public Health Partnership (NPHP). The national falls prevention for older people plan: 2004 onwards. Canberra: NPHP, 2004.

4. Australian Institute of Health and Welfare. Australia's health 2004. Canberra: AIHW, 2004.

5. Commonwealth Department of Health and Family Services and Australian Institute of Health and Welfare. National health priority areas report: injury prevention and control 1997. AIHW Cat. No. PHE 3. Canberra: DHFS and AIHW, 1998.

6. Harrison JE, Steenkamp M. Technical review and documentation of current NHPA injury indicators and data sources. Injury Research and Statistics Series Number 14. Adelaide: AIHW, 2002.

7. Langley J, Stephenson S, Cryer C, Borman B. Traps for the unwary in estimating person based injury incidence using hospital discharge data. Inj Prev 2002; 8: 332-7. doi:10.1136/ip.8.4.332
8. Boufous S, Williamson A. Reporting of the incidence of hospitalised injuries: numerator issues. Inj Prev 2003; 9: 370-5. doi:10.1136/ip.9.4.370

9. Fingerhut LA, Warner M. Injury chartbook. Health, United States, 1996-97. Maryland: National Center for Health Statistics, 1997.

10. Schmertmann ML, Williamson A. NSW injury profile: a review of injury data (1995-1999) and identification of areas requiring further study. Sydney: NSW Injury Risk Management Research Center, 2002.

11. Population Health Division. The health of the people of New South Wales: report of the Chief Health Officer, 2004. Sydney: NSW Department of Health, 2004.

12. Alsop JC, Langley JD. Determining First Admissions in a Hospital Discharge File via Record Linkage. Meth Inform Med 1998; 37: 32-7.

13. National Centre for Classification in Health. The international statistical classification of diseases and related health problems, 10th revision, Australian modification (ICD-10-AM). Volume 5: Australian Coding Standards. 2nd ed. Sydney: NCCH, 2000.

14. Australian Institute of Health and Welfare. National Health Data Dictionary. Version 8.0. Canberra: Australian Institute of Health and Welfare, 1999. 


\section{A review of the efficacy of human $Q$ fever vaccine registered in Australia}

\author{
Clayton K. Chiu ${ }^{\mathrm{A}}$ and David N. Durrheim ${ }^{\mathrm{B}, \mathrm{C}}$ \\ ${ }^{\mathrm{A}} N \mathrm{SW}$ Public Health Officer Training Program, \\ NSW Department of Health \\ ${ }^{B}$ Hunter New England Population Health, \\ Hunter New England Area Health Service \\ ${ }^{\mathrm{C}}$ Corresponding author. \\ Email: David.Durrheim@hnehealth.nsw.gov.au
}

\begin{abstract}
Background: Q fever remains an important occupational zoonosis in rural Australia. Although Q fever vaccine is recommended in highrisk occupational groups, its availability has been limited in recent years. Method: A literature review of the efficacy of the human $\mathrm{Q}$ fever vaccine registered in Australia was conducted. Results: Seven relevant vaccine efficacy studies were identified but no large double-blind, randomised, placebocontrolled studies have been conducted. Vaccine efficacy has ranged from $83-100 \%$ but limitations of study designs hamper a precise estimate of vaccine efficacy. Conclusion: Despite the shortcomings of efficacy studies, the Q fever vaccine available in Australia has considerable protective benefit in established high-risk environments, particularly of an occupational nature.
\end{abstract}

\section{Background}

Disease burden

$\mathrm{Q}$ fever is a zoonosis caused by Coxiella burnetii. It has been identified in a wide range of wild and domestic animal hosts including arthropods, birds, rodents, marsupials and livestock, but the commonest reservoirs are cattle, sheep and goats. C. burnetii can withstand harsh environmental conditions including desiccation, and are shed in excreta, milk and, particularly, birth products of infected animals. ${ }^{1}$

Humans become infected primarily by inhaling aerosols contaminated by $C$. burnetii. Established higher risk occupations include abattoir and farm workers, and veterinarians. Indirect exposures through a contaminated environment or ingestion of contaminated unpasteurised milk have also been recognised but their contribution is not well quantified. ${ }^{1}$ A Victorian study estimated that the average annual risk of $\mathrm{Q}$ fever among abattoir workers to be $62.6 / 1000$ over the initial 10 years of employment. ${ }^{2}$ Unfortunately, there is currently only a limited understanding of the stratification of risk by nature of exposure, the possible variable pathogenicity of different $C$. burnetii strains, and the disease modulating effect of human immune responses.

Many infected people are asymptomatic or only experience a self-limiting febrile illness. Although Q fever infections generally respond to antibiotic treatment, they may result in significant morbidity, including pneumonia, hepatitis, chronic endocarditis and post-Q fever fatigue syndrome, and occasionally death. Recrudescence may occur, especially in pregnant and immunocompromised patients.

Australia reported between 465 and 757 cases annually between 2000 and 2004. This is likely to be an underestimate because of difficulties in diagnosing $\mathrm{Q}$ fever and the current passive disease surveillance system. Data from the Notifiable Diseases Database in NSW, which reported $47 \%$ of all Australian Q fever cases in 2004, indicated that many notified cases still occurred among known high-risk groups. In 2004 and 2005 (to 22 November), 41\% of cases with an identified occupation were farm workers and $13 \%$ were abattoir workers, meat workers, livestock handlers or veterinarians.

\section{Disease control}

A national vaccination program against $\mathrm{Q}$ fever that initially targeted abattoir workers, and subsequently also shearers and people employed on sheep and cattle farms, was conducted in Australia between 2001 and 2004. The program was evaluated by the National Centre for Immunisation Research and Surveillance for the Australian Government Department of Health and Ageing, but the resulting report has not yet been published.

Although environmental containment measures, including environmental cleaning and use of personal protective equipment, are often recommended as adjuncts to vaccination for $\mathrm{Q}$ fever control, no specific studies of the effectiveness of these measures have been conducted.

\section{Human Q fever vaccines}

Three types of vaccine have been proposed for providing human protection against $\mathrm{Q}$ fever: the attenuated live vaccine (produced and trialled in Russia but subsequently 
abandoned because of concern about its safety); chloroform-methanol residue extracted vaccine or other extracted vaccines (trialled in animals but not humans); and the whole-cell formalin-inactivated vaccine, which is considered acceptably safe for humans. ${ }^{3}$ Australia is the only developed country that manufactures this latter $\mathrm{Q}$ fever vaccine on a commercial basis and it has been available in Australia since 1989. Ongoing Q fever vaccine availability in Australia became uncertain during late 2005.

\section{Methods}

A search of the Medline and Embase databases was conducted to identify all published English language articles on the efficacy of the formalin-inactivated Henzerling strain phase I vaccine in humans, using subject headings and keywords: Q fever, Coxiella burnetii, Henzerling, 'Q-vax', vaccine, vaccination and immunisation (and corresponding variants of these keywords). Original reports referenced in articles were also accessed.

\section{Results}

Seven vaccine studies on the efficacy of the formalin-inactivated Henzerling strain phase I vaccine in humans were identified in the literature (Table 1).

One article reported two challenge studies that have been conducted on human volunteers. ${ }^{3}$ The study, performed in the late 1950s, involved 24 subjects and tested an earlier formulation with a three-dose schedule. The reported study conducted between 1966 and 1968 pooled results from two studies conducted in parallel and involved 38 subjects. Both found vaccine efficacy to be $92 \%$, but with broad confidence limits due to the small number of subjects.

A limited, randomised, blinded, placebo-controlled trial of the $\mathrm{Q}$ fever vaccine (using influenza vaccine as a placebocontrol) that utilised a sequential analysis design was conducted in the late 1980s in three Queensland abattoirs with different characteristics. ${ }^{4}$ This study was terminated after 15 months when one-sided $95 \%$ statistical significance was reached between the two study arms, with seven Q fever cases reported in the placebo-control group with no cases in the trial group. The protective efficacy of this vaccine was not estimated in this study. The method of randomisation was not clearly described, nor the intention-totreat principle applied.

A retrospective cohort analysis of a 1998 Q fever outbreak investigation in a southern NSW abattoir during the second phase of a local $\mathrm{Q}$ fever vaccination program provided some useful efficacy information. ${ }^{5}$ Nineteen staff members were vaccinated during the first phase, at least six weeks before the onset of the first outbreak case. No exposure differences were apparent between these
19 people and the 68 susceptible people who were eligible for vaccination during the second phase. Since no Q fever cases occurred in the 19 vaccinated individuals while 37 cases occurred in the 68 unvaccinated individuals, vaccine efficacy was calculated at $100 \%$, although the lower confidence limit cannot be accurately estimated because of absence of cases in the vaccinated individuals.

Three open trials (non-randomised studies without control groups) provided additional insight into the efficacy of the available $\mathrm{Q}$ fever vaccine. ${ }^{6-8}$ Two $\mathrm{Q}$ fever cases were diagnosed among 2553 vaccinated employees from three different abattoirs in South Australia between 1985 and 1990, while 55 cases were reported among 1365 unvaccinated employees during this period, indicating a vaccine efficacy of $98 \%$ with a $95 \%$ lower confidence limit of $92 \%{ }^{6}$ Results may have been affected by volunteer selection bias, uncertain risk exposure estimates and inadequate active $\mathrm{Q}$ fever case ascertainment.

An earlier open trial in three South Australian abattoirs reported four Q fever cases amongst 924 vaccinated workers and 34 cases amongst 1349 unvaccinated workers between June 1981 and January 1983 (Relative risk of vaccinated $(\mathrm{RR})=0.17,95 \%$ CI $0.06-0.48, p=0.00027){ }^{7}$ This study also suffered limitations, as the unvaccinated group included employees who were not enrolled and enrolled volunteers who were not vaccinated, either due to the presence of immune markers or other unstated reasons. The vaccinated group also included a small number of volunteers who had detectable immune markers before vaccination. A greater proportion of unvaccinated workers were deployed in higher risk areas.

A follow-up study of Q fever cases between mid-1981 and 1988 among workers from five different abattoirs in South Australia ${ }^{8}$ included subjects from the study mentioned above. ${ }^{7}$ Some subjects in this study were also included in the study described earlier. ${ }^{6}$ Vaccine efficacy was reported as $100 \%$, with eight $Q$ fever cases among 3532 vaccinated subjects all attributed to exposure before vaccine-induced immunity would have developed. Among the subgroup considered at high risk of exposure, three of 2715 vaccinated subjects developed disease, whereas 52 of 2012 unvaccinated subjects developed disease, a protective efficacy estimate of $96 \%$ (95\% CI 86-99\%, $p<0.0001)$. Analysis of a subgroup of workers from a single abattoir, without immune markers of the disease before contemplating vaccination, revealed two cases of $\mathrm{Q}$ fever among 690 vaccinated individuals and seven cases among 61 unvaccinated subjects, an efficacy estimate of $97 \%$ (95\% CI $88-99 \%, p<0.0001)$.

The only economic study undertaken in Australia on Q fever vaccine predated the completion of the national 


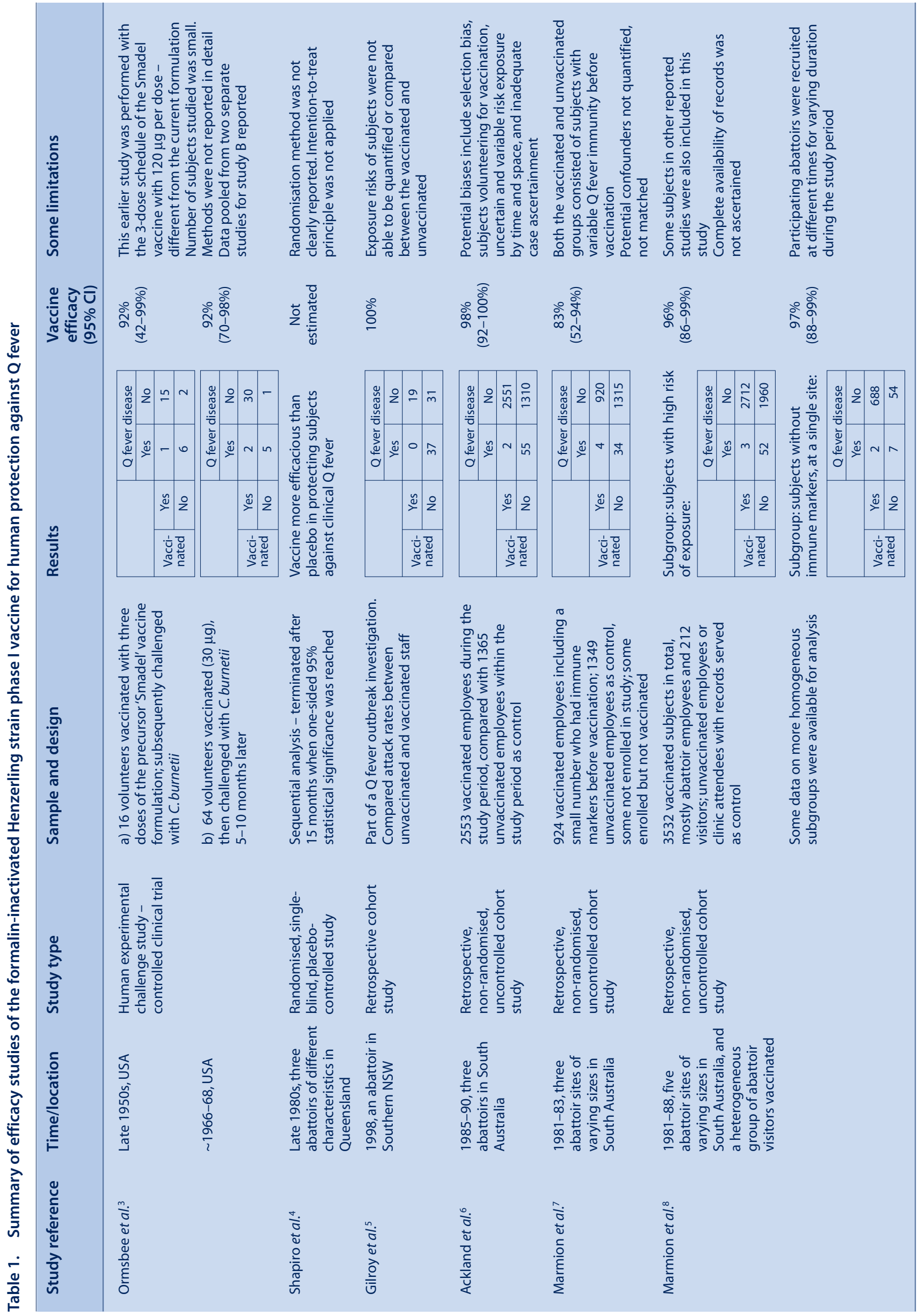


vaccination program and assumed a vaccine efficacy of $98 \%$. It concluded on the basis of direct and indirect costs resulting from Workers' Compensation claims, that application of $Q$ fever vaccine in high risk occupational settings would result in cost savings from a societal perspective. ${ }^{9}$ Extrapolating 1993-94 data from NSW, an Australian review of Q fever conservatively estimated that the disease costs Australia approximately A $\$ 1$ million and more than 1700 weeks of work time lost annually. ${ }^{10}$

\section{Discussion}

Although no large-scale, double-blind, randomised, placebo-controlled studies have evaluated the Australian registered Q fever vaccine, and despite the obvious limitations in the design of published studies, which mean that no precise measure of vaccine efficacy is available, study findings consistently suggest that vaccine efficacy is high compared with other vaccines currently used in Australian public health programs (eg, greater than $80 \%$ for pertussis vaccine, and $\sim 30-80 \%$ for influenza vaccine for older people, depending on the selected outcome indicator). Although uncertainty with respect to the lower efficacy confidence limit may constrain decisions regarding the vaccine's application in lower risk situations, in established high-risk environments, particularly of an occupational nature, it has considerable protective value.

It is important that ongoing availability of an effective Q fever vaccine be ensured for protecting high-risk groups.

\section{Acknowledgements}

Data from the NSW Notifiable Diseases Database was accessed through the Health Outcomes Information and Statistics Toolkit (HOIST) system, a data access, analysis and reporting facility established and operated by the Centre for Epidemiology and Research, Population Health Division, NSW Department of Health

\section{References}

1. Maurin M, Raoult D. Q fever. Clin Microbiol Rev 1999; 12: 518-53.

2. Grieg JE, Patel MS, Clements MS, Taylor NK. Control strategies for $\mathrm{Q}$ fever based on results of pre-vaccination screening in Victoria, 1998 to 2001. Aust N Z J Public Health 2005; 29: 53-7.

3. Ormsbee RA, Marmion BP. Prevention of Coxiella burnetii infection: vaccines and guidelines for those at risk. In: Marrie TJ, editor. Q fever: the disease. Volume 1. Chapter 12. Boca Raton, Florida: CRC Press, 1990.

4. Shapiro RA, Siskind V, Schofield FD, Stallman N, Worswick DA, Marmion BP. A randomized, controlled, doubleblind, cross-over, clinical trial of Q fever vaccine in selected Queensland abattoirs. Epidemiol Infect 1990; 104: 267-73.

5. Gilroy N, Formica N, Beers M, Egan A, Conaty S, Marmion B. Abattoir-associated Q fever: a $\mathrm{Q}$ fever outbreak during a Q fever vaccination program. Aust N Z J Public Health 2001; 25: $362-7$.

6. Ackland JR, Worswick DA, Marmion BP. Vaccine prophylaxis of Q fever. A follow-up study of the efficacy of Q-Vax (CSL) 1985-1990. Med J Aust 1994; 160: 704-8.

7. Marmion BP, Kyrkou M, Worswick D, Esterman A, Ormsbee RA, Wright J, Cameron S, Feery B, Collins W. Vaccine prophylaxis of abattoir-associated Q fever. Lancet 1984; 342: 1411-4. doi:10.1016/S0140-6736(84)91617-9

8. Marmion BP, Ormsbee RA, Kyrkou M, Wright J, Worswick DA, Izzo AA, Esterman A, Feery B, Shapiro RA. Vaccine prophylaxis of abattoir-associated Q fever: eight years' experience in Australian abattoirs. Epidemiol Infect 1990; 104: 275-87.

9. Kermode M, Yong K, Hurley S, Marmion B. An economic evaluation of increased uptake in $\mathrm{Q}$ fever vaccination among meat and agricultural industry workers following implementation of the National Q Fever Management Program. Aust N Z J Public Health 2003; 27: 390-8.

10. Garner MG, Longbottom HM, Cannon RM, Plant AJ. A review of Q fever in Australia 1991-1994. Aust N Z J Public Health 1997; 21: 722-30. 


\section{Bug Breakfast in the Bulletin: Q fever}

\section{Melissa J. Irwin ${ }^{\mathrm{A}}$, Andrew R. Lloyd ${ }^{\mathrm{B}}$ and Peter D. Massey ${ }^{\mathrm{C}}$}

ANSW Public Health Officer Training Program, NSW Department of Health

${ }^{\mathrm{B} S}$ chool of Medical Sciences, University of NSW

${ }^{\mathrm{C}}$ Hunter New England Population Health,

Hunter New England Area Health Service

Q fever is a zoonotic disease caused by the obligate intracellular Gram-negative bacterium Coxiella burnetii. ${ }^{1}$ This Bug Breakfast discussed the disease, natural history and issues affecting population control.

\section{Background}

$\mathrm{Q}$ fever has been described in most countries of the world; however, it is a notifiable disease in only a few. ${ }^{1}$ It has a low infectious dose and survives harsh environmental conditions. ${ }^{2}$ As a result, it has been classified as a group B bioterrorist agent by the US Centers for Disease Control and Prevention (CDC).

Cattle, sheep and goats have been considered the primary human reservoir for $C$. burnetii; however, many other animals including Australian native species are known to be infected. Although most infected animals exhibit very few clinical signs, they shed $C$. burnetii in their milk, urine, faeces and particularly in amniotic fluid and placenta. ${ }^{2}$

Human transmission occurs through inhalation of aerosols of infected body fluids, the ingestion of unpasteurised milk or dairy products, or by inhalation of dried infectious dusts. Person-to-person transmission is rare. Those most at risk of Q fever are abattoir workers, livestock workers and veterinarians, farmers, shearers and laboratory workers. The Australian annual notification rate peaked at 4.9 per 100000 persons in 1993 and decreased to 1.7 per 100000 persons in 2005. ${ }^{3}$ The highest incidence of $Q$ fever occurs in south and central-western Queensland and northern NSW areas with men aged 40-44 years having the highest age-specific rate. ${ }^{4,5}$

\section{Natural history, diagnosis and treatment}

The incubation period for Q fever is usually 19-21 days (range one to six weeks). The illness presents with rapid onset of fevers, chills, profuse sweating, headaches, and muscle and joint pain, although the subclinical to clinical ratio is approximately $3: 1$. Occasionally hepatitis, pneumonia or neurological manifestations may occur in the acute illness. If $C$. burnetii persists, it leads to chronic, localised Q fever infection. Endocarditis (particularly in those with underlying valvular heart disease) is the most common manifestation of chronic, localised infection. In addition, a postinfective fatigue syndrome (in the absence of ongoing infection), termed post-Q fever fatigue syndrome, is commonly reported. ${ }^{6}$

C. burnetii exists in two antigenic phases in laboratory culture systems, Phase I and Phase II. In nature, the organism exists in the Phase I state and is virulent and highly infectious. ${ }^{1}$ Antibodies to both appear in a characteristic order in acute Q fever: IgM Phase II, IgM Phase I, IgG Phase II and then IgG Phase I. The appearance of IgG antibodies may be delayed up to six to eight weeks following the onset of symptoms. ${ }^{7}$

Diagnosis of acute $\mathrm{Q}$ fever requires a high index of clinical suspicion and relies on acute and convalescent serology. Although IgM antibody detection from a single serum sample is convenient, this assay is commonly associated with false positive test results.

Acute Q fever is treated with doxycycline, although rifampicin and ciprofloxacin are also effective. Chronic Q fever is characterised by ongoing illness, localised tissue injury and high titres of Phase I antibodies (IgG and IgA), and requires prolonged treatment with doxycycline, rifampicin and hydrochloroquine.

\section{Population control of $\mathrm{Q}$ fever}

Australia has access to the only licensed vaccine against Q fever available worldwide (QVax, CSL Ltd). Immunisation of high-risk occupational groups has been the major population control method; however, significant gaps remain in our knowledge of the optimal immunisation strategy. The vaccine is a purified suspension of formalininactivated C. burnetii. This vaccine is highly effective, ${ }^{8}$ but its uptake is constrained by the fact that serological and skin testing are required prior to immunisation to prevent hypersensitivity reactions in those who may have been previously exposed. The vaccine produces protection via generation of cellular immunity (rather than antibodies) and is likely to provide lifelong protection.

A Federally-sponsored National Q fever Management Program to support screening and immunisation commenced in 2001 and concluded in NSW in June 2004. ${ }^{9}$ The program resulted in most abattoir workers being immunised; however, many other at-risk rural populations remain unimmunised and account for the majority of notifications in many regions of Australia. Although respira- 
tory precautions and personal protective equipment are likely to provide some protection in high-risk settings, their efficacy in rural working environments has not been evaluated and their practicality is often questionable.

At the time of presenting the $\mathrm{Q}$ fever Bug Breakfast in March 2006, the manufacturer had planned to discontinue the production of QVax. This prompted concern among rural communities and public health professionals. However, in May 2007 the Australian Government and the manufacturer committed to funding the construction of the BP Marmion Q Fever Vaccine Building in Melbourne $^{10}$ to produce and test $\mathrm{Q}$ fever vaccine. It is anticipated to be operational by July 2009. The manufacturer has also stated that vaccine supply will continue until this facility is operational.

Q fever remains a significant public health concern, particularly for rural communities. Despite the commitment to ongoing vaccine supply and testing, further understanding of the risk factors associated with acquiring $\mathrm{Q}$ fever in rural communities is required.

\section{References}

1. Maurin M, Raoult DQ. Fever. Clin Microbiol Rev 1999; 12(4): $518-53$
2. Woldehiwet Z. Q fever (coxiellosis): epidemiology and pathogenesis. Res Vet Sci 2004; 77: 93-100. doi:10.1016/j.rvsc.2003.09.001

3. National notifiable diseases surveillance system. At http://www9.health.gov.au/cda/Source/Rpt_4.cfm, accessed 30 June 2006

4. Garner MG, Longbottom HM, Cannon RM, Plant AJ. A review of Q fever in Australia 1991-1994. Aust N Z J Public Health 1997; 21(7): 722-30.

5. Lin M, Roche P, Spencer J, Milton A, Wright P, Witteveen D, Leader R, Merianos A, Bunn C, Gidding H, Kaldor J, Kirk M, Hall R, Della-Porta A. Australian notifiable disease status 2000. Commun Dis Intell 2002; 26: 1-50.

6. Ayres JG, Flint N, Smith EG, Tunnicliffe WS, Fletcher TJ, Hammond K, Ward D, Marmion BP. Post-infection fatigue syndrome following Q fever. Q J Med 1998; 91(2): 105-23.

7. Worswick D, Marmion B. Antibody responses in acute and chronic Q fever and in subjects vaccinated against Q fever. J Med Microbiol 1985; 19: 281-96.

8. Marmion BP, Ormsbee RA, Kyrkou M, Wright J, Worswick DA, Izzo AA, Esterman A, Feery B, Shapiro RA. Vaccine prophylaxis of abattoir-associated Q fever: eight years' experience in Australian abattoirs. Epidemiol Infect 1990; 104: 275-87.

9. http://www.immunise.health.gov.au/qfever/index.htm, accessed 28 June 2006

10. Q fever vaccine supply. At http://www.csl.com.au/QFever.asp, accessed 4 July 2007. 


\section{Diphtheria}

\section{What is diphtheria?}

Diphtheria is a contagious and potentially life-threatening bacterial infection that usually affects the nose and throat. Diphtheria was a common cause of death in children up until the 1940s but has now almost disappeared in Australia due to immunisation. It is re-emerging as a problem in some areas of the world with poor immunisation rates.

The bacteria that cause diphtheria are called Corynebacterium diphtheriae and Corynebacterium ulcerans. Some of these bacteria also produce a toxin.

\section{What are the symptoms?}

- Symptoms begin two to five days after exposure to the diphtheria bacteria. The first symptoms are usually a sore throat and a mild fever. A membrane forms over the throat and tonsils that can make it hard to swallow and breathe. The infection can also cause the lymph glands and tissues on both sides of the neck to swell.

- A toxin formed by some diphtheria bacteria can cause inflammation of heart muscle and nerves which can be fatal.

- Sometimes diphtheria can cause small skin sores that form larger ulcers, commonly on the legs.

- People usually take between two and five days to show symptoms after infection.

\section{How is it spread?}

- Diphtheria bacteria can live in the mouth, nose, throat or skin of infected individuals.

- People can get diphtheria by breathing in the diphtheria bacteria after an infected person has coughed or sneezed. People can also get diphtheria from close contact with discharges from an infected person's mouth, nose, throat or skin.

- People with diphtheria are infectious for up to four weeks from the onset of symptoms. Some people may become carriers of the bacteria and are infectious for longer.

- C. ulcerans is occasionally associated with consumption of unpasteurised milk or contact with animals.

\section{Who is at risk?}

Anyone who comes in contact with diphtheria during its infectious phase who has not had diphtheria in the past or has not been fully immunised is at risk.

\section{How is it prevented?}

- Diphtheria vaccination protects against the disease. It is part of the standard vaccination schedule and is given as DTP vaccine, which protects against diphtheria, tetanus and pertussis (whooping cough) in combination.

- DTP vaccine should be given at two, four and six months of age, followed by booster doses at four years and at 15 years of age.

- A high vaccination rate must be maintained to protect the population from resurgence of this disease.

\section{How is it diagnosed?}

- A doctor can diagnose diphtheria based on a clinical examination when the membrane is seen in the throat, and by testing throat swabs in a laboratory.

- Special laboratory tests are needed to detect the toxin.

\section{How is it treated?}

Diphtheria infection is treated with antibiotics. Sometimes an antitoxin is also needed.

\section{What is the public health response?}

Laboratories, school principals and directors of childcare centres and hospitals are required to notify cases of diphtheria to the local Public Health Unit under the Public Health Act, 1991. Public Health Units investigate cases and their contacts to review possible sources of infection and prevent further spread. Cases are isolated until they are not infectious. People who have had close or prolonged contact with a case may also be at risk of infection. Some contacts of cases are given antibiotics to stop the infection from developing.

\section{NSW}




\section{Communicable Diseases Report, New South Wales, May and June 2007}

\section{Communicable Diseases Branch, NSW Department of Health}

For updated information, including data and facts on specific diseases, visit www.health.nsw.gov.au and click on Infectious Diseases.

Figure 3 and Tables 1 and 2 show reports of communicable diseases received through to the end of May and June 2007 in NSW.

\section{Meningococcal disease}

Eight cases of meningococcal disease were notified in NSW in each of May and June. The number of case reports of meningococcal disease has fallen steadily in NSW from 253 in 2000 to 104 in 2006 . As the peak season for this disease is approaching, NSW Health recently faxed general practitioners the following key messages:

- Early diagnosis and treatment by GPs can be lifesaving: benzylpenicillin is the treatment of choice for suspected cases, preferably intravenously

- Patients should be reassessed when the diagnosis is uncertain

- Meningococcal C conjugate vaccine is still free for people up to 25 years of age who were not vaccinated during the school vaccination program.

A biweekly review of meningococcal disease, as well as treatment and prevention guidelines, appears at the above website.

\section{Influenza}

Influenza activity increased markedly in the second half of June to moderate levels, as measured by an upturn in the rate of patients attending emergency departments and the number of respiratory specimens from patients that have tested positive for influenza A.

Influenza symptoms include: fever, headache, myalgia, lethargy, coryza, sore throat and cough. Children may also have nausea, vomiting and diarrhoea.

Treatment is largely supportive although neuraminidase inhibitors can decrease the severity and duration of the illness if treatment is commenced within the first 48 hours of the onset of illness.

To help reduce its spread, people with influenza are encouraged to:

- Use tissues and cover the mouth and nose when coughing or sneezing

- Wash hands frequently with soap and running water for 10 seconds, especially after coughing or blowing the nose

- Stay away from school, work and crowded places while unwell.

Influenza vaccine is recommended for:

- All people aged 65 years and older

- Aboriginal people 50 years and older, and younger Aboriginal adults with medical risk factors

- Children (over six months of age) and adults with chronic illnesses

- Residents of nursing homes and other long-term care facilities

- Contacts of high-risk patients.

Influenza vaccination is not recommended by the National Health and Medical Research Council (NHMRC) as a universal population-based vaccination program for children; however, it can be given to people over six months of age who wish to reduce their likelihood of becoming ill with influenza. Full protection is usually achieved within 10 to 14 days of vaccination.

For details, see the weekly review of influenza activity at the above website.

\section{Legionnaires' disease}

Seven cases of legionnaires' disease due to infection with Legionella pneumophila were reported in May and four in June, including two people who died. None of the cases were linked. The number of cases is in line with seasonal expectations.

\section{Enteric diseases \\ May}

Eight outbreaks of food-borne disease were investigated by NSW Public Health Units in May 2007. These outbreaks affected between two and 17 people each, and were linked to four restaurants, three cafés and one aged-care facility. In one outbreak, reported by Sydney West Area Health Service (Penrith office), Salmonella infection was 
identified as the cause of the illness affecting nine people whose common exposure was eating deep-fried ice cream at a restaurant. Further investigation of the source of ingredients used in the deep-fried ice cream is underway.

There were 27 outbreaks of gastrointestinal disease in institutions reported in NSW in May. These outbreaks included 17 aged-care facilities, five child-care centres, two hospitals and one school. Viruses were confirmed as the cause in seven outbreaks (rotavirus in one and norovirus in six), and the remaining 20 had clinical and epidemiological features consistent with viral gastroenteritis. These features can include nausea, vomiting, diarrhoea, fever, abdominal pain, headache and muscle aches and a high secondary attack rate.

Norovirus is the most commonly reported cause of diarrhoeal outbreaks in aged-care facilities in NSW, and rotavirus is a common cause of viral gastroenteritis outbreaks in child-care centres. Control depends on early recognition that an outbreak is occurring; exclusion (or isolation) of infectious cases; careful hand washing; care with food preparation and environmental cleaning.

For more information about norovirus, see:

http://www.health.nsw.gov.au/infect/pdf/viral_gastro.pdf.

For information about rotavirus see:

http://www.ncirs.usyd.edu.au/facts/rotavirus_vaccine_

for_children_sep_2006.pdf

For guidelines on managing outbreaks in institutional settings see: http://www.health.nsw.gov.au/pubs/2004/ gastroctrl_fs.html.

\section{June}

NSW Public Health Units investigated nine suspected food-borne disease outbreaks in June. These outbreaks were reported to affect between two and 10 people and occurred after people had eaten food from a café, restaurant or takeaway outlet. Scombroid poisoning was suspected to be the cause of illness in two people who ate grilled tuna. Their symptoms resolved following treatment with antihistamines. In most of the other outbreaks, there was insufficient evidence to identify specific pathogens or food items causing illness, and viral infection remains a likely cause for many of the illnesses.

Twenty outbreaks of gastroenteritis in institutions affecting more than 350 people were notified in June. The settings for these outbreaks were: aged-care facilities (11), child-care facilities (7), a hospital and a residential institution. Norovirus was confirmed to be the cause of four of the outbreaks, all in aged-care facilities. Although viral gastrointestinal disease in institutions tends to increase during winter, the rates of illness appears to be lower this year compared to 2006 .

\section{Statewide outbreak of cryptosporidiosis in NSW,} November 2005-May 2006

\section{Kerri A. Viney and Jeremy M. McAnulty \\ Communicable Diseases Branch, NSW Department of Health}

Cryptosporidiosis is a diarrhoeal disease caused by the intestinal parasite, Cryptosporidium. ${ }^{1}$ There are several species of cryptosporidium, but two species, Cryptosporidium parvum and Cryptosporidium hominis, are thought to be responsible for the majority of infections in humans. ${ }^{2}$ Humans are thought to be the major reservoir for C. hominis, while C. parvum infects humans and a range of animals including livestock. ${ }^{3}$

The major symptom of cryptosporidiosis is diarrhoea, which may be profuse and watery and is often associated with cramping abdominal pain. The incubation period is one to 12 days and a person with cryptosporidiosis may excrete oocysts for several weeks after symptoms resolve. ${ }^{1}$ The mode of transmission is the faecal-oral route and includes animal-to-person, person-to-person, water-borne and rarely, food-borne transmission. ${ }^{1}$ Outbreaks have been associated with swimming pools, drinking water supplies and, occasionally, consumption of contaminated beverages. ${ }^{1}$

Cryptosporidium has been notifiable to the NSW Health Department since 1996, and several outbreaks linked to swimming in contaminated pools have been identified. ${ }^{4-7}$ Several hundred cases of cryptosporidiosis are reported in NSW each year and the number of cases tends to increase in the warmer months.

In November 2005, analysis of routinely collected notification data by NSW Health identified a sharp increase in the number of people with cryptosporidiosis: 114 cases were reported in November, up from 28 in October. Initial interviews with cases indicated that an unusually high number $(28 \%)$ had reported contact with animals or farms. We received anecdotal reports from a NSW District veterinarian of concurrent cryptosporidiosis in calves with considerable numbers of oocysts detected in the faeces of sick calves. NSW Health subsequently issued a media release warning of the risk of cryptosporidiosis following contact with farm animals, urging people to take care with hygiene after animal contact, and (to avoid contamination of swimming pools) advising people not to swim if they had had diarrhoea in the previous week. To identify the reasons for the increase in notifications, we initiated a descriptive study of cases in NSW notified between 1 November 2005 and 29 May 2006.

\section{Methods}

A case of cryptosporidiosis was defined as a resident of NSW who had a laboratory confirmed case of cryptosporidiosis, and who was notified between 1 November 
2005 and 29 May 2006. Demographic characteristics of notified cases were routinely entered into NSW Health's Notifiable Diseases Database (NDD). We asked NSW Public Health Units to interview all cryptosporidiosis cases notified between 1 November 2005 and 29 May 2006 with a standard questionnaire in order to identify potential risk factors including attendance at preschool, contact with another case, contact with pets and farm animals and farm visits. These data were entered into Net Epi Case Manager, a web-based database developed by the Centre for Epidemiology and Research (NSW Health). ${ }^{8}$ NDD and Net Epi data were then analysed using SAS. ${ }^{9}$ We analysed cases by exposure, date of onset, report date, area of residence, gender and age group. We ranked exposures in the following order: contact with farm animals (including farm visits), swimming, contact with another case and other exposure (such as preschool attendance, contact with pets and drinking untreated water).

\section{Results}

In December 2006, 844 cases of cryptosporidiosis were reported between 1 November 2005 and 29 May 2006. From November, cases of cryptosporidiosis occurred at higher than expected rates: 119 cases were reported in December, 104 in January, 130 in February, 179 in March, 109 in April and 89 to 29 May 2006. The epidemic curve shows a peak of cases in the weeks commencing 27 November and 12 March (Figure 1).

\section{Demographic characteristics}

Of all 844 cases, 397 (47\%) resided in metropolitan Sydney and 53\% in the remainder of NSW. The majority of the cases reported between 1 November 2005 and 31 December 2005 resided in areas outside of metro- politan Sydney (233; 96\%); this number fell to 267 (44\%) among cases reported from 1 January to 29 May 2006. Overall, higher numbers were reported in the Northern Sydney, Hunter, South Eastern Sydney and Northern Rivers Areas (pre-2005 AHS boundaries).

Of all cases, $49 \%$ were male and $51 \%$ female. By age group, $41 \%$ of cases were aged $0-4$ years, $18 \%$ were aged $5-9$ years, $8 \%$ of cases were aged $10-19$ years, $20 \%$ were aged $20-34$ years and $13 \%$ were aged 35 or over.

\section{Reported exposures}

Of the 844 cases, PHU staff interviewed 464 (55\%) about possible exposures. The most frequent exposures reported by cases in the two weeks before onset of signs and symptoms were: pet contact $(59 \%)$, swimming $(55 \%)$, preschool attendance (26\%), drinking untreated water (20\%) (of whom 67\% drank tank water), other animal contact (21\%) and visiting a farm (18\%). Almost one third (30\%) of cases reported contact with either another possible or notified case. The usual drinking water source at home was reported as town water for the majority of cases (75\%), but $11 \%$ also reported drinking tank water at home; $5 \%$ of cases also reported drinking tank water at work or another place.

Over time, the number of cases reporting specific exposures changed (Figure 2). Swimming remained an important exposure throughout the period. The proportion of cases that reported swimming as an exposure peaked in January (58\%) and decreased sharply in April (10\%). Farm visits and contact with farm animals were more prominent exposures in the earlier stages of the outbreak (in November $2005,21 \%$ reported contact with farm animals or visiting a farm), although some cases also reported these exposures in

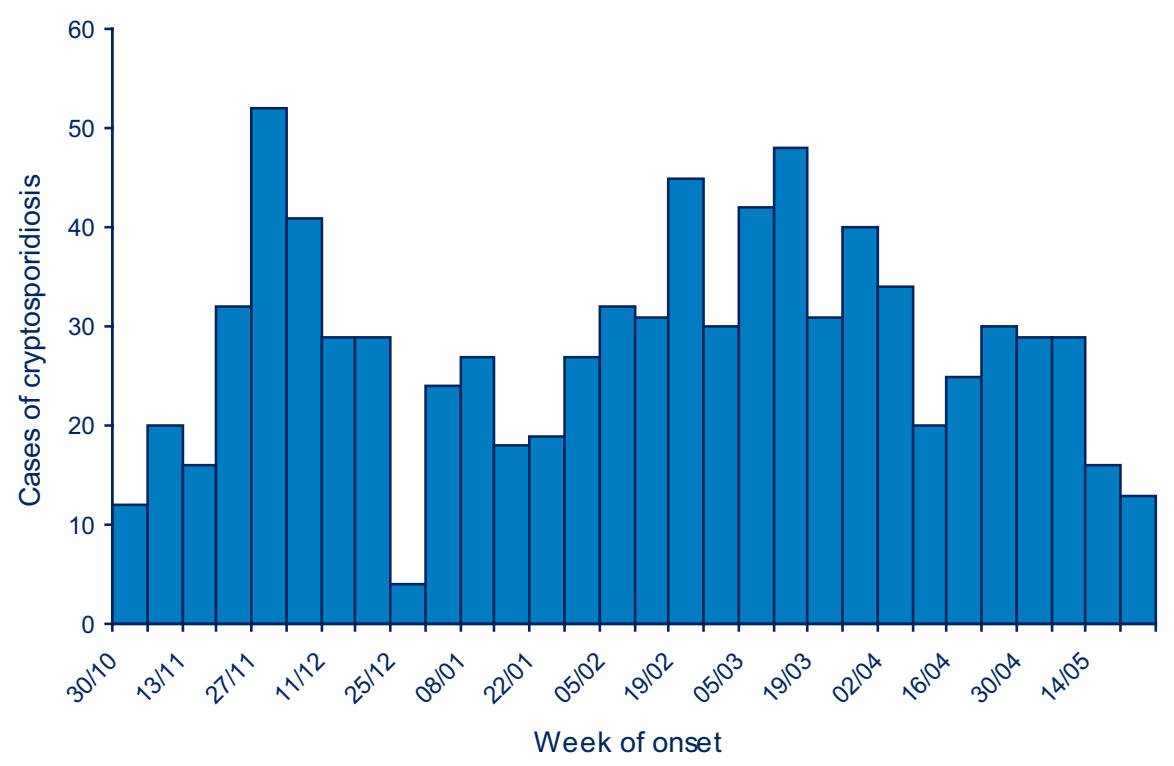

Figure 1. Cases of cryptosporidiosis notified in NSW, 30 October 2005 to 27 May 2006 (by onset date). Source: NSW Health Notifiable Diseases Database 


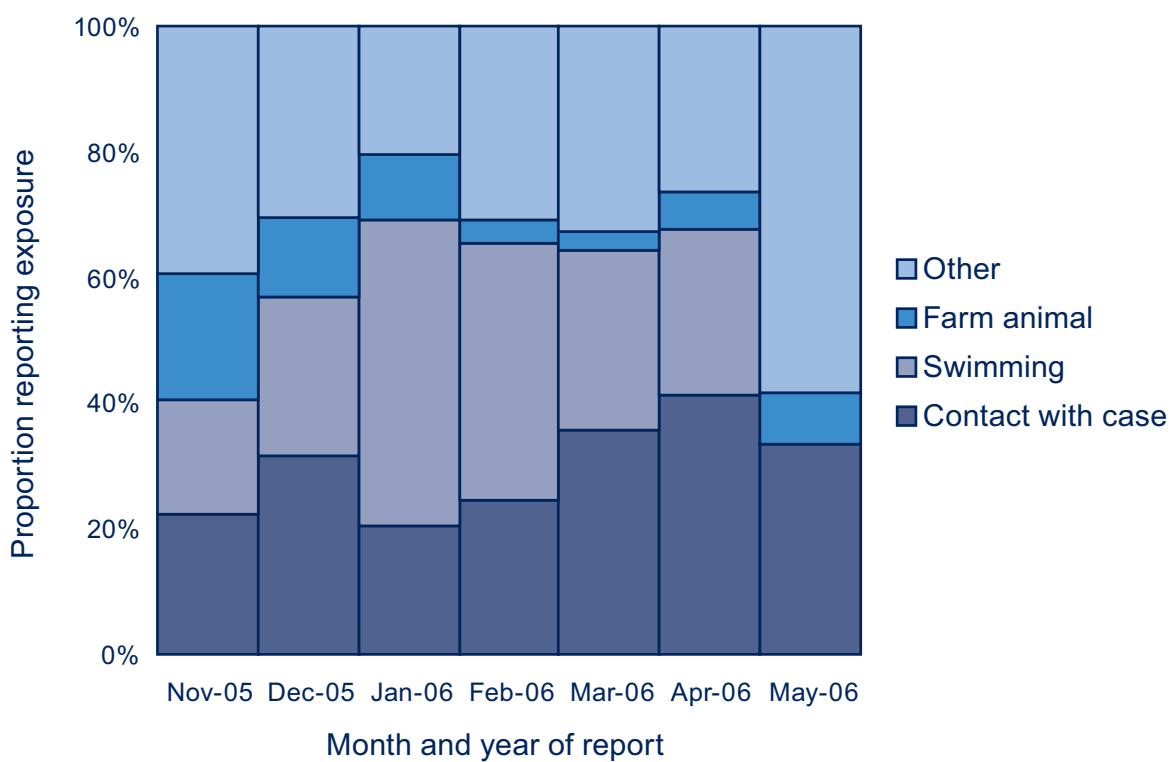

Figure 2. Exposures of cryptosporidiosis cases (as proportion of total) in NSW by month of report, 1 November 2005 to 29 May 2006 (only one exposure reported for each case)

December (8\%) and January (7\%). In November, a small number of cases (six) reported direct contact with scouring calves on their properties. The proportion of cases that reported contact with a possible or notified case peaked in March (42\%), and varied from $20 \%$ in January to $42 \%$ in March. Preschool attendance was also reported consistently throughout the period ( $15 \%$ on average), with a lower proportion of cases reported in December and January as could be expected in holiday periods.

Prior to December 2005, the majority of cases were outside of metropolitan Sydney and in 2006, the proportion fell to under half. Also, prior to December 2005, a greater proportion of cases reported a farm visit or contact with farm animals than in early 2006 and swimming as an exposure was reported by a greater proportion of people in December and January.

\section{Comment}

In this outbreak a large proportion of cases reported swimming, pet contact, preschool attendance, farm visits, animal contact or contact with another case in their incubation period. The number of cases reporting specific exposures changed over time and may reflect changing risk in the course of the outbreak. Patterns of changing geographical distribution and changing exposures in this outbreak support the hypothesis that much of the outbreak began in rural areas of NSW where contact with farms and animals were risk factors, then over time spread via contamination of swimming pools and person-to-person contact.

A limitation in this analysis is a lack of a comparison group, which makes it difficult to draw causal links between exposures and illness. In addition, in recent years, two species of Cryptosporidium: C. hominis and C. parvum have been recognised to infect people. The laboratory data do not allow us to differentiate between the contributions each of them made in this outbreak. It may be that a high proportion of the cases identified earlier in this outbreak were C. parvum (associated with farm animals) than later (when person-to-person and swimming pool spread predominated in the outbreak).

Cryptosporidiosis transmission can be prevented by careful hand washing, avoidance of drinking contaminated drinking and pool water, and avoidance of swimming in pools while infectious. In light of an outbreak in 2007, the Centre for Health Protection conducted a poster campaign designed to educate swimmers about hygiene and pools.

In future outbreaks it would be useful to gather information on cryptosporidiosis species on cases from differing geographical areas and with different exposures in order to ascertain the relative contribution that the species make in outbreaks, and determine the geographical distribution of the two species.

\section{References}

1. Heymann DL. Control of Communicable Diseases Manual 18th ed. Washington DC: American Public Health Association, 2004.

2. Xiao L, Fayer R, Ryan U, Upton SJ. Cryptosporidium taxonomy: Recent advances and implications for public health. Clin Microbiol Rev 2004; 17(1): 72-97. doi:10.1128/CMR.17.1.72-97.2004

3. Caccio SM, Thompson RCA, McLauchlin J, Smith HW. Unravelling Cryptosporidium and Giardia epidemiology. 
Trends Parasitol 2005; 21(9): 430-7. doi:10.1016/j.pt.2005.06.013

4. Puech MC, McAnulty JM, Lesjak M, Shaw N, Heron L, Watson JM. A statewide outbreak of cryptosporidiosis in New South Wales associated with swimming at public pools. Epidemiol Infect 2001; 126(3): 389-96. doi:10.1017/S0950268801005544

5. Black M, McAnulty J. The investigation of an outbreak of cryptosporidiosis in New South Wales in 2005. N S W Public Health Bull 2006; 17(5-6): 76-9.

6. Lemmon JM, McAnulty JM, Bawden-Smith J. Outbreak of cryptosporidiosis linked to indoor swimming pool. Med J Aust 1996; 165(11-12): 613-6.
7. Stafford R, Neville G, Towner C. McCall B. A community outbreak of Cryptosporidium infection associated with a swimming pool complex. Commun Dis Intell 2000; 24(8): 236-9.

8. NSW Department of Health. NetEpi Case Manager Quick Reference Guide. At https://wwwepi3.health.nsw.gov.au/patontraining/help/help.html\#login, accessed 15 February, 2007.

9. SAS Institute. The SAS system for Windows version 8.02. Cary, NC: SAS Institute, 2003.

Erratum. In the Communicable Diseases Report for January and February 2007 (N S W Public Health Bull 2007; 18(3-4):69) the following correction should be made.

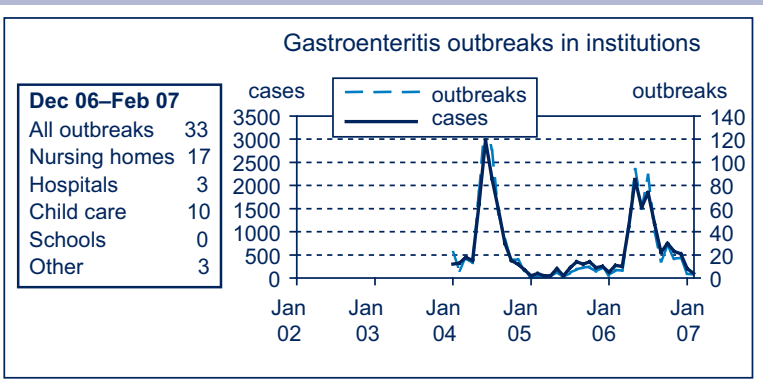


Figure 3. Reports of selected communicable diseases, NSW, Jan 2002 to June 2007, by month of onset.

Preliminary data: case counts in recent months may increase because of reporting delays.

Laboratory-confirmed cases only, except for measles, meningococcal disease and pertussis.

BFV, Barmah Forest virus infections; RRV, Ross River virus infections; Lab Conf, laboratory confirmed;

Men Gp C and Gp B, meningococcal disease due to serogroup C and serogroup B infection; Other/unk, other or

unknown serogroups. NB: multiple series in graphs are stacked, except gastroenteritis outbreaks.

Outbreaks are more likely to be reported by nursing homes and hospitals than by other institutions.
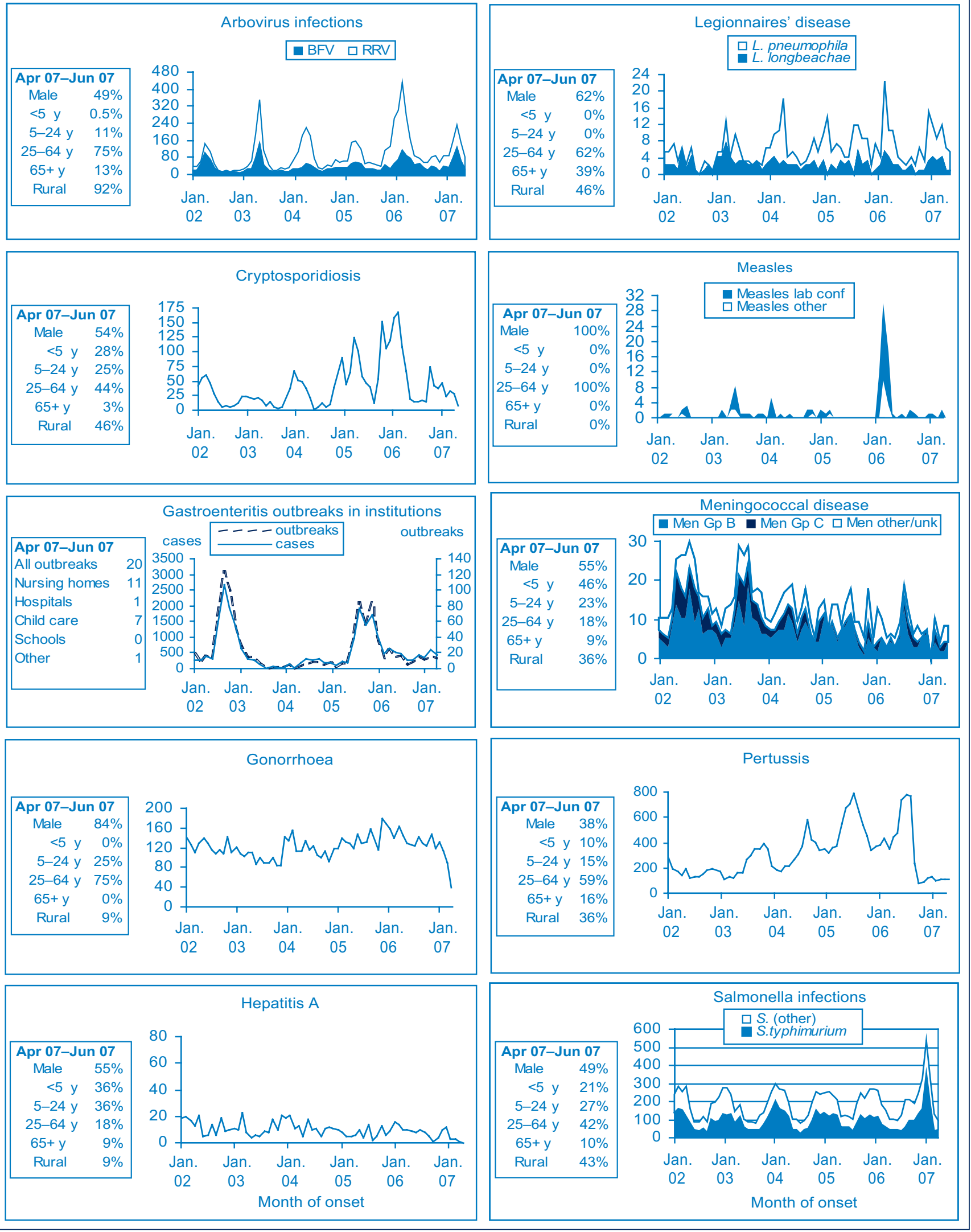
Table 1. Reports of notifiable conditions received in May 2007 by Area Health Services

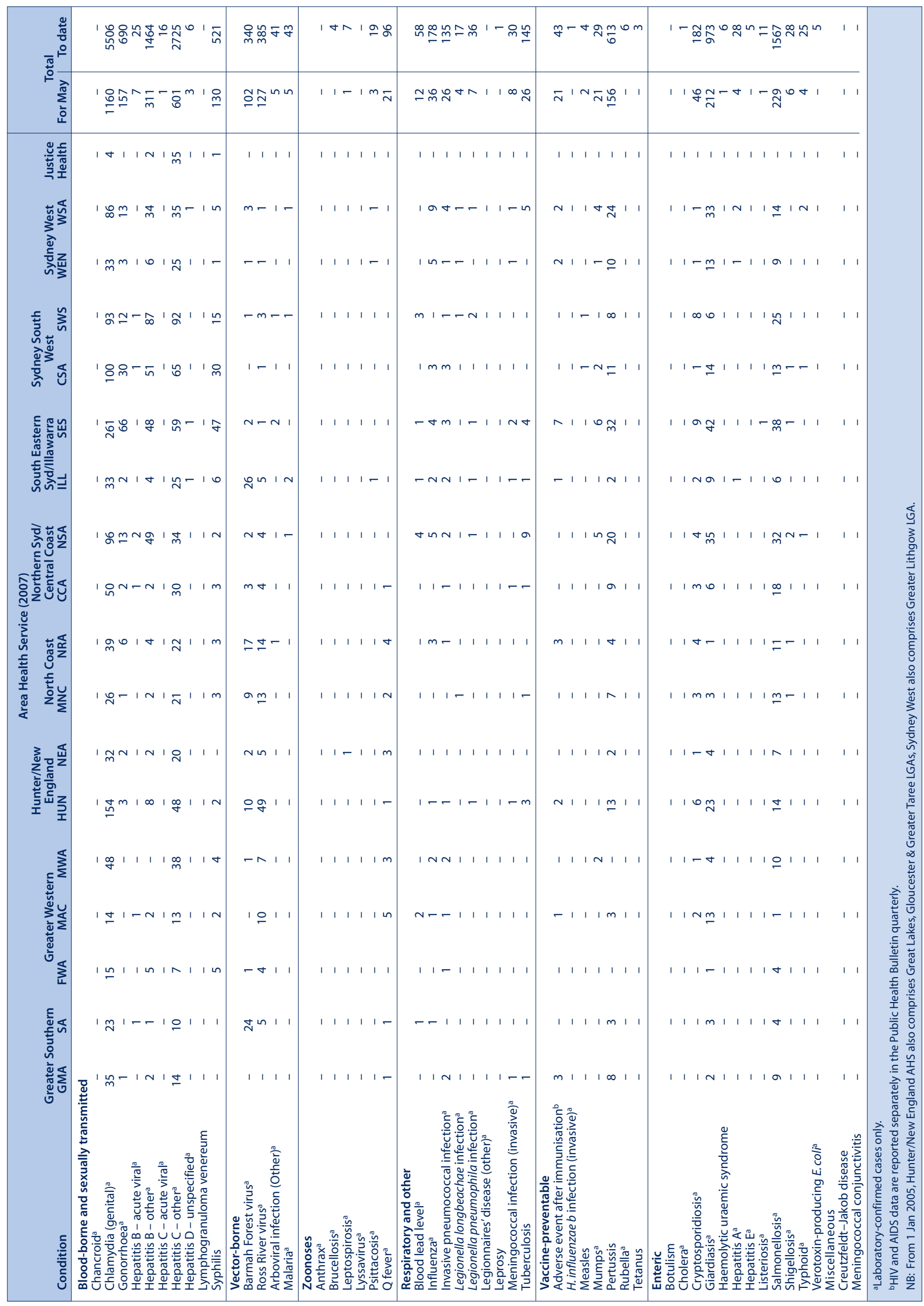


Table 2. Reports of notifiable conditions received in June 2007 by Area Health Services

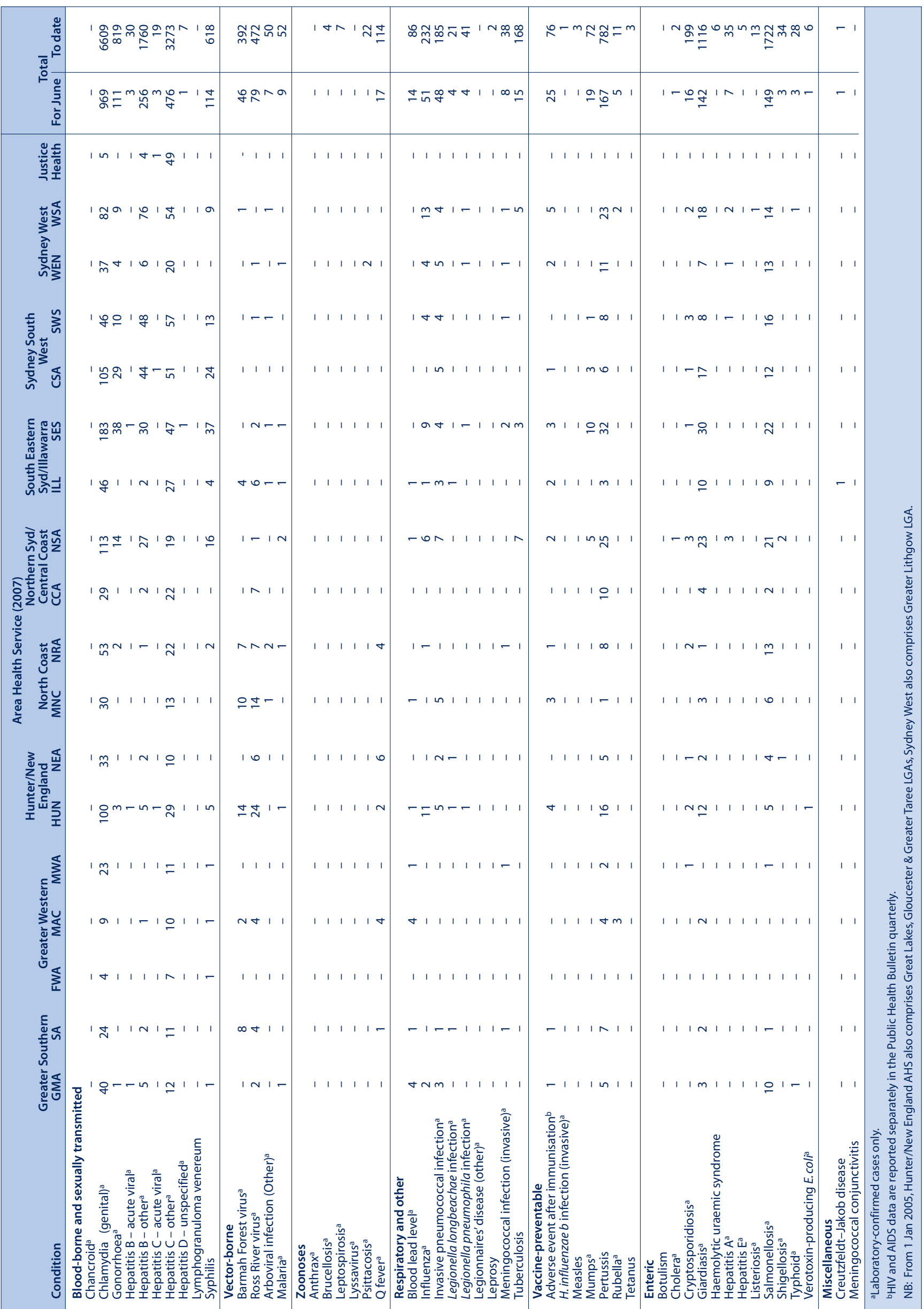




\section{Contents}

\section{Special issue: Year in review}

105 Year in review: communicable disease surveillance, New South Wales, 2006

Presents the trends in reports of notifiable diseases among NSW residents for 2006.

Communicable Disease Branch, NSW Department of Health

115 Enhanced surveillance of hepatitis B infection in inner-western Sydney

A surveillance system for hepatitis B to improve the detection of newly acquired cases and to collect epidemiological data is described.

Bradley L. Forssman, Leena Gupta

119 Prevalence of Mantoux positivity and annual risk of infection for tuberculosis in Australian prisoners, 1996 and 2001

The study compares the prevalence of Mantoux positivity in NSW prisoners and examines factors associated with infection with Mycobacterium tuberculosis.

Michael H. Levy, Tony G. Butler, Jialun Zhao

125 Recent substance use and high levels of psychological distress among secondary school students in New South Wales

An analysis of the data from the 2002 NSW School

Students Health Behaviours Surveys suggests a significant minority of students appeared to be at high risk.

Tom F. Norris, Margo L. Eyeson-Annan
130 A discussion of the potential benefits to injury surveillance through inclusion of date of injury in hospitalisation data in New South Wales and Australia The availability of a 'date of injury' item in routine hospital separations data in NSW and Australia could provide improved injury surveillance, increasing the value of the information used to support injury prevention and control in NSW and Australia.

Andrew D. Hayen, Soufiane Boufous, James E. Harrison

133 A review of the efficacy of human $Q$ fever vaccine registered in Australia

Despite the shortcomings of vaccine efficacy studies in this literature review, the $\mathrm{Q}$ fever vaccine registered in Australia has considerable protective benefit in established high-risk environments, particularly in occupational settings.

Clayton K. Chiu, David N. Durrheim

Bug Breakfast in the Bulletin

137 Q Fever

Melissa J. Irwin, Andrew R. Lloyd, Peter D. Massey

Factsheet

139 Diphtheria

Communicable Diseases Report, New South Wales

140 May and June 2007

\section{NSW PUBLIC HEALTH BULLETIN}

The NSW Public Health Bulletin is a peer-reviewed journal produced by the NSW Department of Health and indexed in Medline. It has a NSW focus, however, it aims to support the practice of public health more broadly.

\section{Editor}

Dr Lynne Madden

BSc(Med)Hons1, MBBS, MPH, MSc, FFPH, FAFPHM

\section{Acting Editor}

Kerri Viney

$\mathrm{RN}, \mathrm{MPH}$

\section{Editorial correspondence}

Please address all correspondence and submissions to:

The Editor, NSW Public Health Bulletin Locked Mail Bag 961

North Sydney NSW 2059 Australia
Email:phbulletin@doh.health.nsw.gov.au Telephone: +61 294245876

Fax:+61 293919232

\section{Submission of articles}

The Bulletin accepts proffered and commissioned articles along with short reports, on all aspects of public health. Articles should be 1500-2000 words, not including tables and figures, and should include an abstract of up to 100 words. Articles should follow the journal style and layout as closely as possible, as described in the Instructions to Authors. Articles should be emailed in a Word for Windows format to:phbulletin@doh.health.nsw.gov.au, and should be accompanied by a covering letter signed by all authors and a License to Publish. The Instructions to Authors, License to
Publish and other useful information can be downloaded from the Bulletin website.

\section{Distribution}

The Bulletin is freely available from the Bulletin website. Copies of the current issue and back issues can be downloaded in both PDF and HTML formats. If you would like to be notified when new issues of the Bulletin are available online, subscribe to the early alert email system at the Bulletin website. The early alert email contains the contents of each new issue along with electronic links to the articles. To receive a printed copy of the Bulletin, subscribe online at the Bulletin website, or contact your local public health unit or the editorial office.

Website: www.publish.csiro.au/journals/phb Copyright @ 2007 NSW Department of Health 